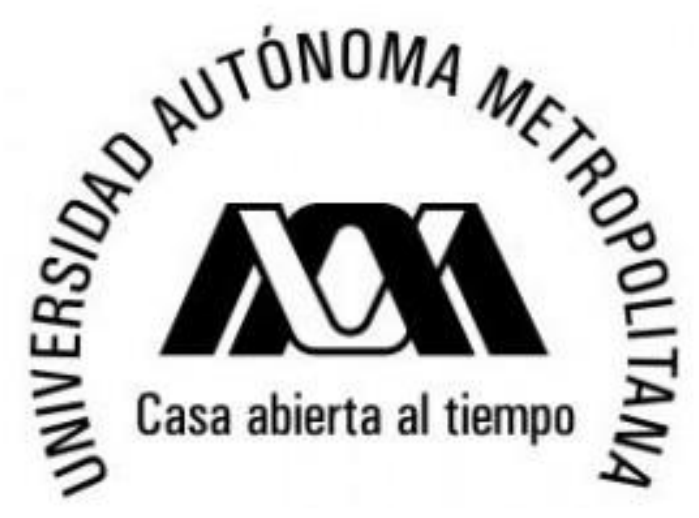

DIVISIÓN DE CIENCIAS BIOLÓGICAS Y DE LA SALUD

\title{
Evaluación de la eficiencia de producción del biosurfactante de Acinetobacter bouvetii a partir de diferentes fuentes de carbono hidrofóbicas
}

$$
\begin{array}{lllll}
\mathrm{T} & \mathrm{E} & \mathrm{S} & \mathrm{I} & \mathrm{S}
\end{array}
$$

Presenta la Universidad Autónoma Metropolitana para obtener el grado:

Maestro en Biotecnología

Por

Néstor David Ortega de la rosa

Director

Dr. Mariano Gutiérrez Rojas

Asesores

Dr. Sergio Huerta Ochoa

Dr. Carlos Omar Castillo Araiza

Noviembre 2013 
La maestría en Biotecnología de la Universidad Autónoma Metropolitana está incluida en el Programa Nacional de posgrados de Calidad (PNPC) de CONACyT con la referencia 001465. 
México, D. F. a 22 de noviembre de 2013

El jurado designado por la División de Ciencias Biológicas y de la Salud de la Unidad

Iztapalapa aprobó la tesis:

Evaluación de la eficiencia de producción del biosurfactante de Acinetobacter bouvetii a partir de diferentes fuentes de carbono hidrofóbicas

Que presentó el estudiante:

Nestor David Ortega de la Rosa

Comité Tutorial

Director: Dr. Mariano Gutiérrez Rojas

Asesor: Dr. Sergio Huerta Ochoa

Asesor: Dr. Carlos Omar Castillo Araiza

Jurado

Presidente: Dr. Sergio Huerta Ochoa

Secretario: Dr. Carlos Omar Castillo Araiza

Vocal: Dra. Patricia Olguín Lora

Vocal: Dr. Manuel Alejandro Lizardi Jiménez 
EVALUACION DE LA EFICIENCIA DE PRODUCCION DEL

BIOSURFACTANTE DE

Acinetobacter bouvetil A

PARTIR DE DIFERENTES FUENTES

DE CARBONO HIDROFOBICAS

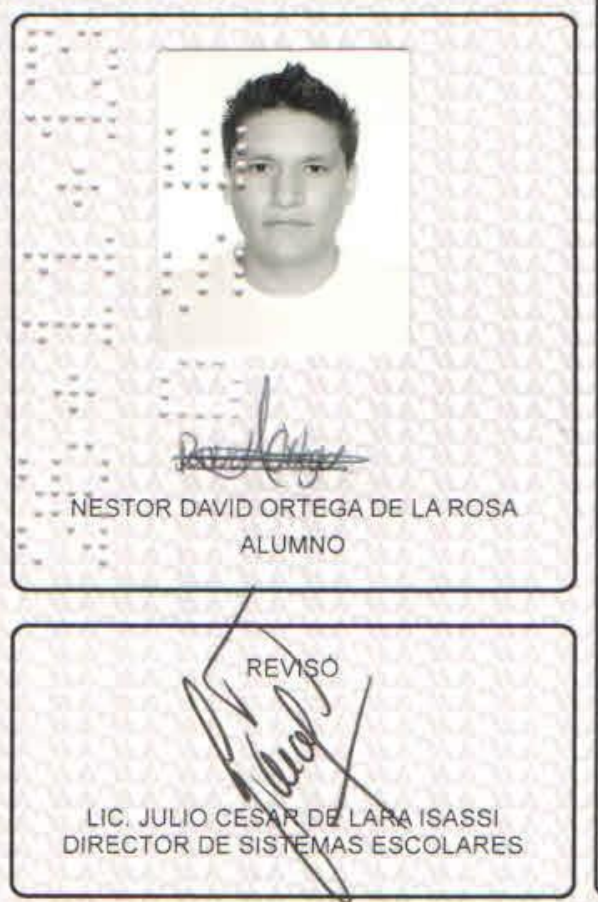

Bajo Ia presidencia del primero y con carácter de Secretario el ultimo, se reunieron para proceder al Examen de Grado cuya denominación aparece al margen, para la obtención del grado de:

MAESTRO EN BIOTECNOLOGIA

DE: NESTOR DAVID ORTEGA DE LA ROSA

$y$ de acuerdo con el articulo 78 fracción II del Reglamento de Estudios superiores de la Universidad Autónoma Metropolitana, los miembros del jurado resolvieron:

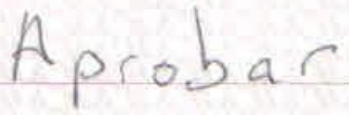

Acto continuo, el presidente del jurado comunicó al interesado $e l$ resultado de la evaluación $y$, en caso aprobatorio, le fue tomada la protesta.

DIRECTORA DE LA DIVISION DE CBS
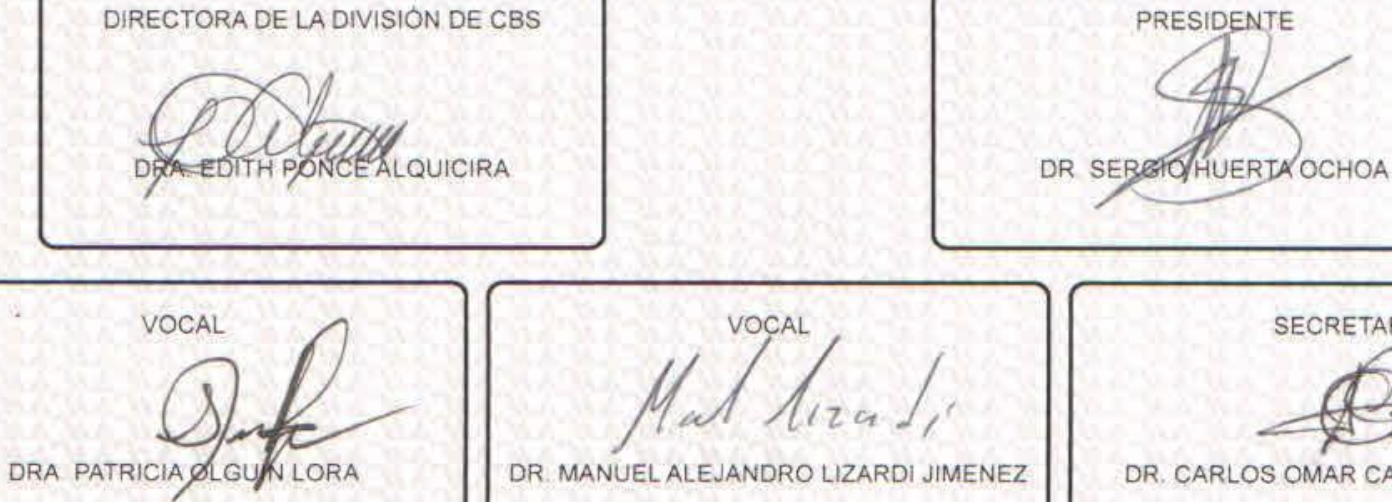

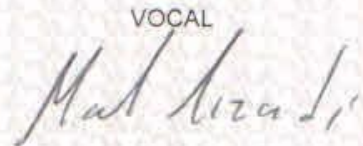

DR. MANUEL. ALEJANDRO LIZARDI JIMENEZ

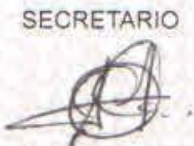

DR. CARLOS OMAR CASTHLLO ARAIZA 
"Un pueblo sin conocimiento de su historia, origen y cultura es como un árbol sin raíces."

Marcus Garvey

\section{Ah tlamiz noxochiuh}

Ah tlamiz noxochiuh

ah tlamiz nocuic

in nocon ya ehua

zan nicuicanitl.

Xexelihui moyahua

cozahuia xochitl:

ye on calaquilo

zacuan calitic.

Nezahualcoyotzin

(1402-1472)

\section{No acabarán mis flores}

No acabarán mis flores,

no acabarán mis cantos:

yo los elevo:

no más soy un cantor.

¡Se reparten, se difunden,

amarillecen las flores:

ya son llevadas

dentro de una mansión de doradas plumas!

Nezahualcóyotl

Traductor: Ángel M. Garibay 
Para ti que siempre has estado a mi lado, Para ti que has tocado mi almá I cambiado mi mundo, Para ti que no te conouco pero revolucionaras mi pensamiento, Para ti Hauriel que transformaste, transformas y transformarás mi vida enterá. 


\section{AGRADECIMIENTOS}

A la Universidad Autónoma Metropolitana por ser mi hogar y no sólo una casa de estudios.

Al Dr. Mariano Gutiérrez Rojas: por la oportunidad, el apoyo y la confianza para formar parte del grupo de investigación de residuos sólidos. Por su dirección, consejos y paciencia durante la realización de este estudio. Especialmente, por su amistad y cariño.

Al Dr. Sergio Huerta Ochoa y al Dr. Carlos Omar Castillo por contribuir al desarrollo de este trabajo con su enriquecedora asesoría, experiencia y conocimientos brindados.

Al Dr. Manuel Alejandro Lizardi Jiménez por la revisión de este documento, por luchar sin abandonar y sobre todo por su amistad.

A la Dra. Patricia Olguín Lora por la revisión de este trabajo.

Al Dr. Jaime Vernon por sus conocimientos compartidos para la comprensión y estudio de las emulsiones.

A la Dra. Gloria Trejo por su asesoría y conocimientos compartidos en la identificación del aceite usado de cocina.

A mis compañeros del laboratorio por su apoyo, consejos y observaciones para mejorar este estudio, particularmente a Olivia Tzintzun, Víctor Sánchez y José Luis Vázquez. 


\section{AGRADECIMIENTOS}

A mi familia por estar siempre conmigo, en especial a mis padres y mi hermana por su amor y cariño.

A Abigail López por ser mi mejor amiga y consejera durante poco más de 13 años en los que hemos pasado malos, buenos y mejores momentos. Por regalarme lo más valioso de mi vida a pesar de mi ceguera y egoísmo. Por tu cariño y comprensión. GRACIAS.

A Nohemí García y Eduardo Ortega por su apoyo y amistad incondicional que ha prevalecido hasta en los momentos más adversos.

A Caliope M. Alquisira por la invaluable crítica constructiva de este trabajo y de mi persona. Por tu amistad y sobre todo por tu "inesperado cariño".

A mis primos Hugo Mendoza y Gustavo Serrano por su cariño y por esos momentos de felicidad que regocijan el corazón y se quedan grabados en el alma.

A mis amigos por compartir sus vidas conmigo, especialmente a Alejandra Méndez, Wylma Pérez, Ana Juárez, Gabriel Hernández, León Sánchez y Erick Sosa. 


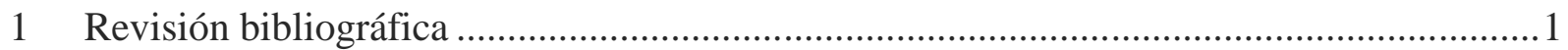

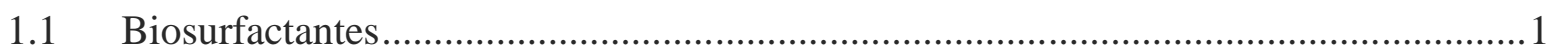

1.2 Fuentes potenciales de carbono para la producción de biosurfactantes..........................3

1.2.1 Fuentes de carbono hidrofóbicas renovables ......................................................

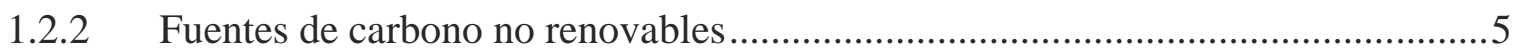

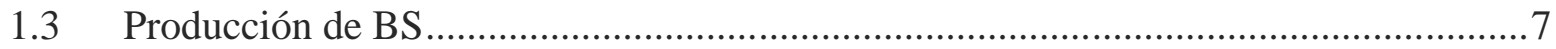

1.4 Acinetobacter bouvetii: Productor de biosurfactante …................................................

1.5 Relevancia científica y originalidad del estudio ........................................................

2 Planteamiento del problema .......................................................................................... 11

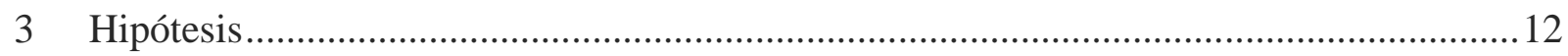

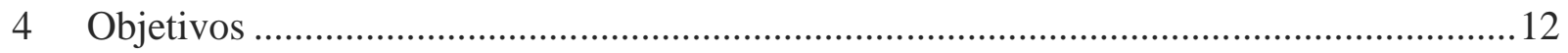

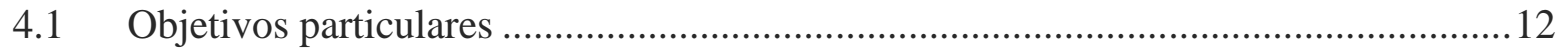

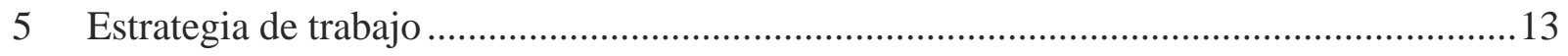

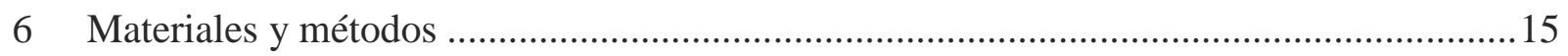

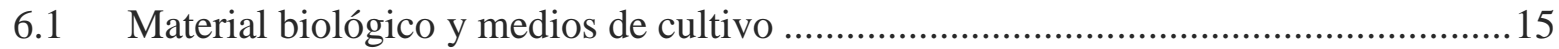

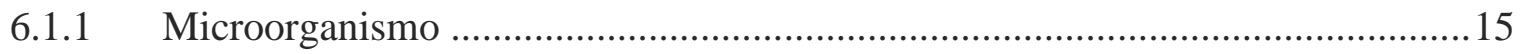

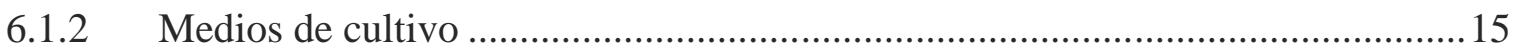

6.1.3 Activación de A. bouvetii.................................................................................15

6.2 Producción de biosurfactante a partir de distintas fuentes de carbono .........................16

6.2.1 Fuentes de carbono hidrofílicas .................................................................... 16

6.2.2 Fuentes de carbono hidrofóbicas ..................................................................... 16

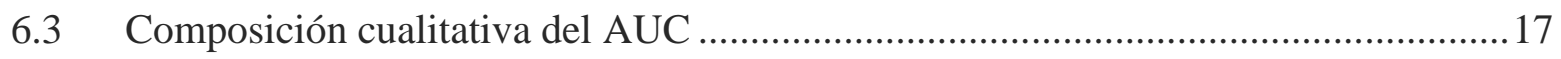

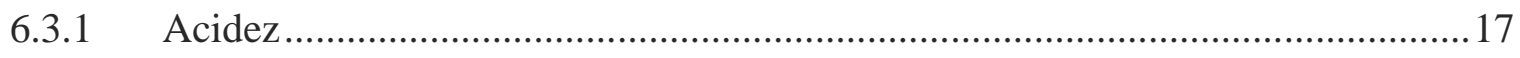

6.3.2 Reacción de transesterificación ...........................................................................18

6.3.3 Cromatografía de gases y espectrometría de masas ..............................................18

6.4 Producción del BS de A. bouvetii en un Biorreactor Airlift .......................................19

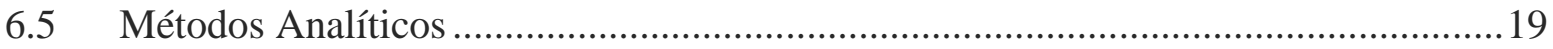

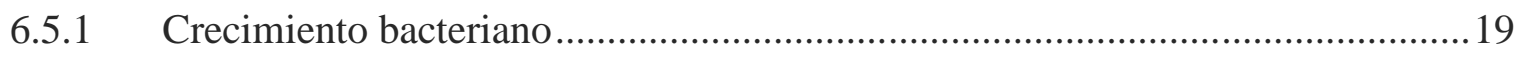

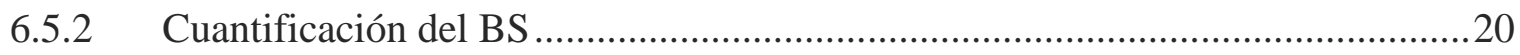




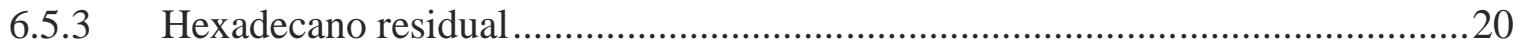

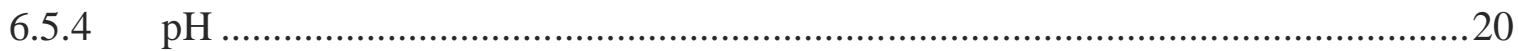

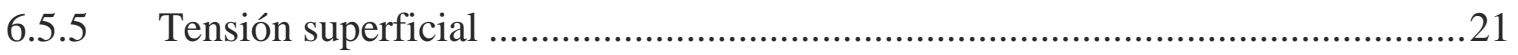

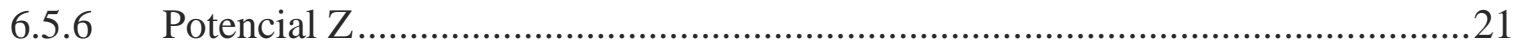

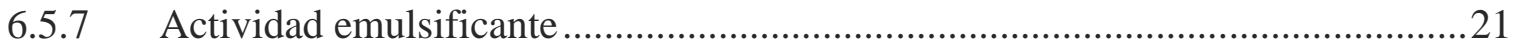

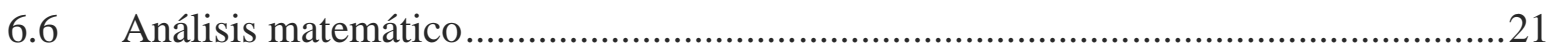

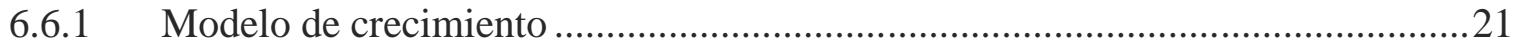

6.6.2 Selección de la mejor fuente de carbono hidrofóbica para la producción del BS

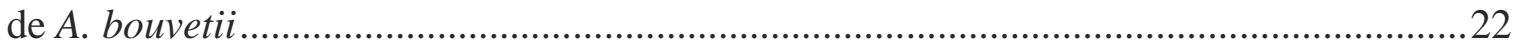

6.6.3 Modelo de producción exponencial máximo …………………………………..26

6.6.4 Estimación del costo de producción de biosurfactante...........................................27

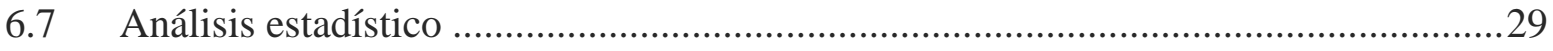

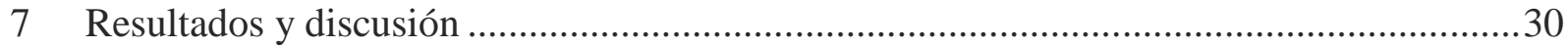

7.1 Producción del biosurfactante de A. bouvetii a partir de distintas fuentes de carbono 30

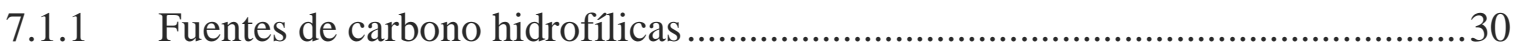

7.1.2 Fuente de carbono hidrofóbica de referencia ......................................................31

7.1.3 Fuentes de carbono hidrofóbicas .........................................................................36

7.2 Selección de la mejor fuente de carbono para la producción del biosurfactante de $A$.

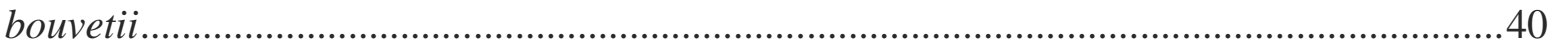

7.2.1 Caracterización cualitativa del aceite usado de cocina..........................................41

7.3 Producción del BS de A. bouvetii en un biorreactor airlift .........................................42

7.3.1 Cinética de crecimiento de A. bouvetii en un biorreactor Airlift...........................43

7.3.2 Parámetros cinéticos de crecimiento de A. bouvetii en un bioreactor airlift. .......45

7.3.3 Actividad emulsificante del biosurfactante de A. bouvetii producido en BAL ...46

7.4 Análisis de costos de producción del BS de A. bouvetii a partir de diferentes fuentes

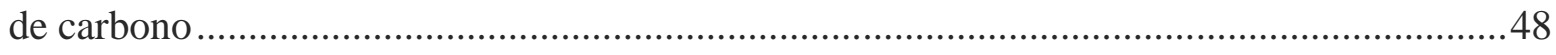

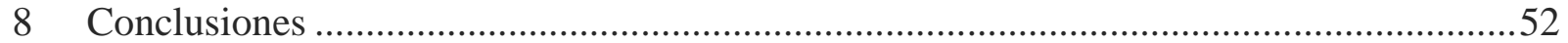

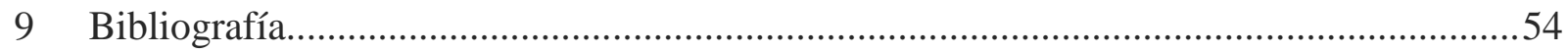


Figura 1. Acumulación de BS en la interfase líquido y aire. 1

Figura 2. Reporte histórico de publicaciones científicas y número de citas por año, indexadas en Web of Science relacionadas con: biosurfactantes (a y b); biosurfactantes y Acinetobacter (c y d); biosurfactantes y Acinetobacter y fuentes de carbono hidrofóbicas (e y f).

Figura 3. Estrategia experimental.

Figura 4. Cinética de producción del BS ( ), crecimiento de A. bouvetii ( $\square$ ) y consumo de n-hexadecano (•). Cada punto representa el valor promedio de tres repeticiones y las barras el error estándar.

Figura 5. Evolución de tensión superficial ( $\Delta$ ) durante la cinética de producción de BS ( $\diamond)$. Cada punto representa el valor promedio de tres repeticiones y las barras el error estándar.

Figura 6. Evolución del pH (+) durante la cinética de producción de BS y Potencial Z ( $\nabla$ ) del sobrenadante libre de células (48 $\mathrm{h}$ de cultivo) a diferentes $\mathrm{pH}$.

Figura 7. Cinéticas de crecimiento de A. bouvetii y curvas ajustadas con el modelo de Gompertz. AH ( ),

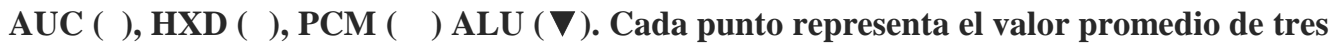
repeticiones y el error estándar. Letras diferentes indican diferencias significativas $(\alpha=0.05$, prueba Tukey)

Figura 8. Actividad emulsificante del BS de A. bouvetii producido a partir de distintas fuentes de carbono. AH ( ), AUC ( $\diamond$, PCM ( ) y ALU ( $\nabla)$. Cada punto representa el valor promedio de tres repeticiones y el error estándar. Letras diferentes indican diferencias significativas $(\alpha=0.05$, prueba Tukey).

Figura 9. Cromatograma de ión total (izq.) y composición de ácidos grasos presentes en el AUC (der.).... 42

Figura 10. Cinéticas de crecimiento de $A$. bouvetii ajustadas con el modelo de Gompertz. Crecimiento: en botella serológica ( $\diamond$ y curva (línea continua), en BAL a Ug alta ( $x$ ) y curva ( ), en BAL a Ug baja ( ) y curva (-). Cada punto representa el valor promedio de tres repeticiones y el ES. Letras diferentes indican diferencias significativas $(\alpha=0.05$, prueba Tukey). 
Figura 11. Cinética de AE ajustadas al modelo de producción. AE: en botella serológica ( y curva (línea continua), en BAL a Ug alta ( $($ ) y curva ( ), en BAL a Ug baja ( ) y curva (-). Cada punto representa el valor promedio de tres repeticiones y el error estándar. 46

Figura 12. Estimación del costo (USD) de producción del BS de A. bouvetii (SBs) en función de: (a) la concentración final de $\mathrm{BS}\left(\mathrm{C}_{\mathrm{BS}}\right)$ y precio de la $\mathrm{FC}\left(\mathrm{S}_{\mathrm{FC}}\right)$, (b) la $\mathrm{C}_{\mathrm{BS}}$ y del porcentaje del costo de

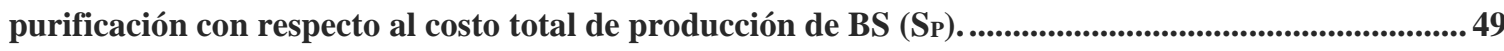

Figura 13. Costo de producción del BS de $A$. bouvetii $\left(\mathrm{S}_{\mathrm{BS}}\right)$ a partir de distintas fuentes de carbono............51

Índice de tablas

Tabla 1. Parámetros cinéticos de crecimiento de A. bouvetii estimados con el modelo de Gompertz. ............38

Tabla 2. Matriz de decisión para elegir la mejor fuente de carbono para la producción del BS. 41

Tabla 3. Parámetros cinéticos de crecimiento estimados con el modelo de Gompertz en distintos biorreactores. Letras diferentes indican diferencias significativas $(\alpha=0.05$, prueba Tukey). .45

Tabla 4. Parámetros de AE estimados con el modelo de producción exponencial máximo en diferentes biorreactores. Letras diferentes indican diferencias significativas ( $\alpha=0.05$, prueba Tukey) 47 


\section{Evaluación de la eficiencia de producción del biosurfactante de Acinetobacter bouvetii a partir de diferentes fuentes de carbono hidrofóbicas}

Palabras clave: biosurfactante, Acinetobacter bouvetii, fuentes de carbono hidrofóbicas, biorreactor airlift.

RESUMEN

Las actividades industriales y agrícolas generan productos y residuos hidrofóbicos de difícil degradación que en contacto con el ambiente generan contaminación. Estas sustancias hidrofóbicas pueden ser utilizadas como fuentes de carbono de bajo costo para producir biosurfactantes. El interés por los biosurfactantes ha ido en aumento debido a: (i) su naturaleza amigable con el ambiente, (ii) su potencial aplicación en las industrias alimentaria, farmacéutica y petrolera así como (iii) en biorremediación de sitios contaminados con compuestos orgánicos hidrofóbicos.

En el presente estudio se evaluó el uso de cuatro fuentes de carbono hidrofóbicas para la producción del biosurfactante (BS) de Acinetobacter bouvetii. Para la evaluación se llevó a cabo un estudio de factibilidad técnica y económica. La factibilidad técnica se determinó con base en los siguientes parámetros técnicos de producción del BS: actividad emulsificante máxima $\left(\mathrm{AE}_{\max }\right)$, máximo crecimiento de $A$. bouvetii $\left(\mathrm{X}_{\max }\right)$, tasa máxima especifica de crecimiento $\left(\mu_{\max }\right)$, duración de fase lag $(\lambda)$ y cambio en la densidad poblacional (D). Los parámetros técnicos se estimaron a partir de cinéticas de producción de BS en botellas serológicas. Se seleccionó la mejor fuente de carbono (FC) con base en criterios de viabilidad y se realizaron cinéticas de producción en un biorreactor airlift (BAL) con la FC seleccionada para validar los parámetros técnicos estimados en las botellas serológicas. La factibilidad económica se 
determinó en función de un análisis de costos de producción del BS de A. bouvetii por medio de un modelo matemático.

A. bouvetii asimiló aceite de higuerilla (AH), aceite usado de cocina (AUC), aceite lubricante usado (ALU) y petróleo crudo Maya (PCM) como única fuente de carbono y energía. Se observó que la producción del BS estuvo parcialmente ligada al crecimiento de A. bouvetii. Los mejores parámetros técnicos de crecimiento (mayores $X_{\max }, \mu_{\max }, \mathrm{D}$ y menores $\lambda$ ) se observaron al utilizar $\mathrm{AH}$ y $\mathrm{AUC}$ como $\mathrm{FC}$, la mayor $\mathrm{AE}_{\max }$ se determinó con el $\mathrm{BS}$ producido a partir de AUC (9.04 $\left.\pm 0.46 \mathrm{UE} \mathrm{mL}^{-1}\right)$. Se seleccionó el AUC como la mejor FC para la producción del BS de $A$. bouvetii a partir de criterios de viabilidad generales, económicos y tecnológicos. Los parámetros técnicos $\left(\mathrm{AE}_{\max }, \mathrm{X}_{\max }, \mathrm{D}\right.$ y $\left.\lambda\right)$ determinados en botella serológica y en BAL no fueron diferentes. El tiempo de cultivo en el BAL disminuyó de 72 a 36 h debido a que la $\mu_{\max }$ se duplicó $\left(0.42 \mathrm{~h}^{-1}\right)$. Se estimó el costo de producción de BS a partir de AUC en $148 \mathrm{USD} \mathrm{kg}^{-1}$, un costo de producción 1.8 veces menor al BS comercial Emulsan. Por lo anterior, se demostró la factibilidad económica de la producción del BS de A. bouvetii.

La principal aportación de este estudio fue demostrar la factibilidad técnica y económica de la producción de biosurfactante de A. bouvetii utilizando fuentes de carbono hidrofóbicas. Así como el estudiar por primera vez el biosurfactante producido por A. bouvetii y determinar que es un bioemulsificante de carácter aniónico. Además, con el modelo matemático propuesto es posible determinar las condiciones necesarias para reducir al mínimo el costo de producción del BS con diferentes FC. 
Keywords: Biosurfactant, Acinetobacter bouvetii, Hydrophobic carbon sources, Airlift bioreactor.

ABSTRACT

Industrial and agricultural activities generate polluting hydrophobic products and residues hard to be degraded. Such hydrophobic substances can be used as low-cost carbon sources able to produce biosurfactants. Interest in biosurfactants has increased due to: (i) their environmentally friendly nature, (ii) their potential application in the food, pharmaceutical and petroleum industries, as well as (iii) in bioremediation of hydrophobic compounds contaminated sites.

In the present study four hydrophobic carbon sources for biosurfactant (BS) production by Acinetobacter bouvetii were evaluated. To achieve the task, a technical and economic feasibility study was developed. The technical feasibility was determined based on the following technical parameters: maximum emulsification activity $\left(\mathrm{AE}_{\max }\right)$, maximum growth $\left(\mathrm{X}_{\max }\right)$, maximum specific growth rate $\left(\mu_{\max }\right)$, lag time $(\lambda)$ and relative population size (D). Technical parameters were estimated from BS production kinetics in serological bottles. The best carbon source (FC) was selected based on viability criteria. The production kinetic runs were performed in airlift bioreactor (BAL) with the selected carbon source to validate the technical parameters previously estimated. Economic feasibility was determined based on an analysis of BS production costs by means of a mathematical model.

A. bouvetii assimilated castor oil (AH), used cooking oil (AUC), used lubricating oil (ALU) and Maya crude oil (PCM) as the sole energy and carbon source. BS production was partially associated to A. bouvetii growth. The best technical parameters of growth (higher $\mathrm{X}_{\max }, \mu_{\max }, \mathrm{D}$ and lower $\lambda$ ) were observed when using AH and AUC as FC. The highest AEmax was determined with BS produced from AUC $\left(9.04 \pm 0.46 \mathrm{UE} \mathrm{mL}^{-1}\right)$. AUC was selected as the best FC for BS 
production by A. bouvetii from general, economic and technological viability criteria. Technical parameters $\left(\mathrm{AE}_{\max }, \mathrm{X}_{\max }, \mathrm{D}\right.$ and $\left.\lambda\right)$ determined in BAL and serological bottles were not different. The cultivation time decreased in BAL from 72 to $36 \mathrm{~h}$ because $\mu_{\max }$ was doubled $\left(0.42 \mathrm{~h}^{-1}\right)$. BS production cost from AUC was estimated in $148 \mathrm{USD} \mathrm{kg}^{-1}$, a production cost 1.8 times less than the commercial BS Emulsan. Therefore, the economic feasibility of BS production by A. bouvetii was demonstrated.

The main contribution of this work was developed to prove the technical and economic feasibility of biosurfactant production by A. bouvetii when using hydrophobic carbon sources. Another contribution of this work was identified as the first study of biosurfactant produced by A. bouvetii which was found to be an anionic bioemulsifier. Moreover, with the proposed mathematical model it is possible to determine the necessary conditions to minimize the BS production cost with different FC. 


\section{Revisión bibliográfica}

\subsection{Biosurfactantes}

Los surfactantes son productos químicos con uso en una gran variedad de aplicaciones industriales. Se estima que la producción mundial de surfactantes en 2007 fue alrededor de 10 millones de toneladas (Van Bogaert y col., 2007). La mayoría de los surfactantes se derivan del petróleo y se sintetizan químicamente. Sin embargo, la tendencia hacia el uso de tecnologías amigables con el medio ambiente, ha fomentado la búsqueda de compuestos biodegradables de origen natural. Por lo tanto, los biosurfactantes (BS) son la elección natural ya que poseen ventajas sobre los surfactantes sintéticos, tales como menor toxicidad, biodegradabilidad y la eficacia en una amplia gama de valores de $\mathrm{pH}$ y temperatura (Banat y col., 2010; Cameotra y col., 2010).

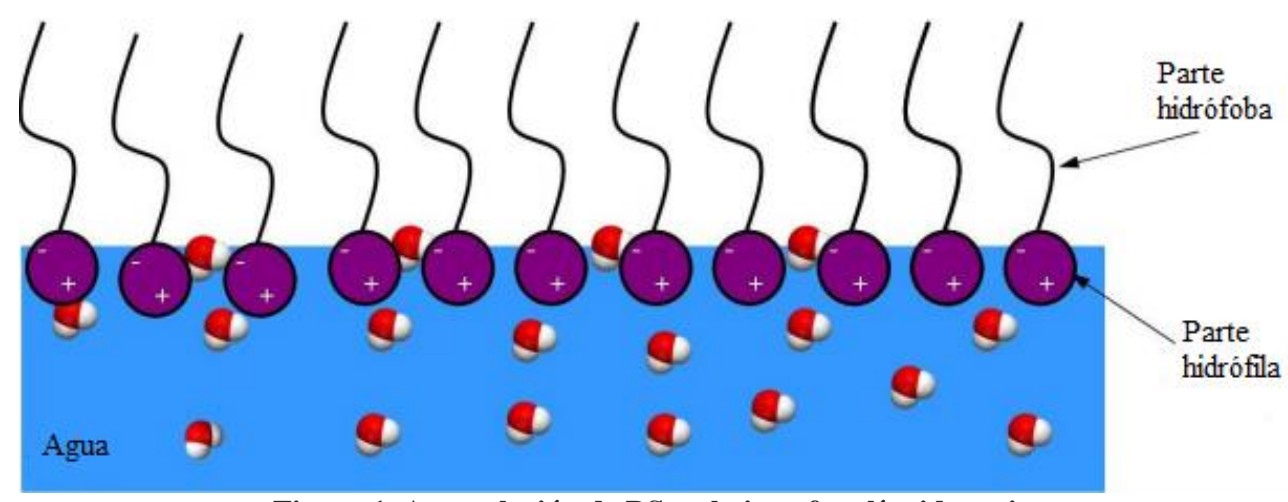

Figura 1. Acumulación de BS en la interfase líquido y aire.

Los BS son moléculas anfifílicas que tienen extremos tanto hidrófilos como hidrófobos que preferentemente se acumulan en las interfases líquido-líquido, gas-líquido o sólido-líquido. En la Figura 1 se muestra un esquema que pretende explicar la naturaleza anfifílica de los BS (Pacwa-Plociniczak y col., 2011). Los BS tienen propiedades emulsificantes, espumantes, detergentes y dispersantes. Los emulsificantes son grupos de moléculas que pueden formar 
mezclas moderadamente homogéneas de dos líquidos inmiscibles. Estos compuestos pueden reducir la tensión superficial ya que simplemente pueden enlazar moléculas hidrofóbicas a hidrofílicas para formar una emulsión. Un espumante es una molécula que se concentra en una interfase gas-líquido lo cual conduce a la formación de burbujas. Un detergente es una sustancia que tiene la propiedad química de disolver suciedad o impurezas de un objeto sin causar corrosión. Un dispersante es un material que reduce la atracción cohesiva entre partículas similares (Satpute y col., 2010).

Los BS más activos pueden disminuir la tensión superficial del agua desde su valor normal 72 hasta $30 \mathrm{mN} \mathrm{m}^{-1}$ y la tensión interfacial entre agua y n-hexadecano (HXD) desde 40 hasta $1 \mathrm{mN}$ $\mathrm{m}^{-1}$ (Desai y Banat, 1997). La funcionalidad, es decir, la capacidad emulsificante, espumante, detergente o dispersante del BS depende de su concentración en el medio en el que se encuentre. En concentraciones por encima de la concentración micelar crítica (CMC), las moléculas de BS tienden a asociarse para formar micelas, bicapas y vesículas. La formación de micelas de BS reduce la tensión superficial e interfacial de esta forma aumenta la solubilidad y la biodisponibilidad de compuestos orgánicos hidrófobos (Whang y col., 2008). La CMC se utiliza comúnmente para medir la eficiencia de los espumantes o tensoactivos. Los BS eficientes tienen una baja $\mathrm{CMC}$, lo que significa que es necesario emplear menos biosurfactante para disminuir la tensión superficial (Desai y Banat, 1997). Por las destacadas características positivas anteriormente mencionadas es necesario disminuir el elevado costo de producción de BS mediante una selección cuidadosa de las posibles fuentes de carbono y energía para las bacterias productoras de BS y así favorecer sus posibles aplicaciones en las industrias alimentaria, farmacéutica, petrolera y en la biorremediación de sitios contaminados con hidrocarburos. 


\subsection{Fuentes potenciales de carbono para la producción de biosurfactantes}

El uso de fuentes de carbono costosas, concentraciones de productos limitados, bajos rendimientos y la formación de mezclas de productos en lugar de los compuestos puros son factores que elevan los costos de producción de biosurfactantes. La principal estrategia para lograr reducir los costos de producción es a través de: (i) la evaluación del sustrato apropiado para cada organismo y el uso de sustratos baratos o de residuos para reducir los costos de materias primas que participan en el proceso, (ii) el desarrollo de bioprocesos eficientes y rentables, incluyendo la optimización de las condiciones de cultivo y los procesos de separación para maximizar la recuperación; y (iii) el desarrollo de cepas mutantes superproductoras o recombinantes para mejorar los rendimientos (Mukherjee y col., 2006; Makkar y col., 2011).

El BS Surfactina (98\% de pureza) disponible de Sigma Chemical Company en 2011 tenía un precio de venta aproximado de 153 dólares estadounidenses (USD) cada vial de $10 \mathrm{mg}$, el costo del caldo que contiene el BS Emulsan en 1997 se estimó en 50 USD kg$^{-1}$ (Rosenberg y Ron, 1997). En comparación, el costo de surfactantes químicos es de alrededor de 2 USD kg-1 . Sin embargo, cuando se toman en cuenta los daños ambientales que puede provocar, en última instancia, el costo se vuelve mucho más de 2 dólares. El escenario comercial competitivo sería contar con que el costo de producción del BS se sitúe en el rango 6-10 dólares $\mathrm{kg}^{-1}($ Makkar y col., 2011).

Para que la aplicación de los BS sea rentable, es necesario el uso de materias primas de bajo costo. El enorme potencial asociado con el uso de desechos y residuos peligrosos de carácter hidrofóbico todavía no se ha aprovechado y resulta conveniente en la búsqueda de sustratos de bajo costo para la producción de BS. La sociedad moderna produce gran cantidad de residuos 
de materiales a través de las actividades relacionadas con las industrias, la silvicultura, la agricultura y de los municipios. Para fines prácticos los posibles sustratos hidrofóbicos se pueden clasificar de acuerdo a su origen en fuentes de carbono renovables y fuentes de carbono no renovables (Kosaric, 1992; Makkar y col., 2011).

\subsubsection{Fuentes de carbono hidrofóbicas renovables}

Entre los sustratos renovables que se han utilizado para la producción de BS destacan los aceites de origen vegetal. Los aceites vegetales son una fuente de carbono lipídica y son en su mayoría derivados de ácidos grasos saturados o insaturados de 16-18 átomos de carbono. Se han utilizado diversos aceites vegetales como los de canola, maíz, girasol, cártamo, de oliva, de colza, semillas de uva, palma, coco, pescado y de soya. La producción mundial de aceites y grasas es de unos 2.5-3 millones de toneladas, $75 \%$ se derivan de las plantas y las semillas de oleaginosas (Dumont y Narine, 2007).

\subsubsection{Aceite de higuerilla o de ricino.}

La higuerilla (Ricinus communis L) es una planta oleaginosa que se encuentra ampliamente distribuida en México, es rústica y se adapta a las condiciones climáticas de diferentes ambientes, además posee un alto potencial de producción para la obtención de aceite (MartínezValencia y col., 2011). El aceite de higuerilla (AH) o de ricino es un líquido viscoso miscible en alcohol y ácido acético glacial, de densidad $0.9537 \mathrm{~g} \mathrm{~mL}^{-1}$ a $25^{\circ} \mathrm{C}$. Debido a su estructura química, el aceite de higuerilla puede ser utilizado como materia prima para la producción de una amplia gama de productos finales como pinturas, detergentes, insecticidas, nylon, resinas plásticas, cueros artificiales, biocombustibles, bactericidas, fungicidas, grasas lubricantes para motores de altas revoluciones, espumas, cosméticos, medicinas y hasta la elaboración de 
prótesis humanas. India, China y Brasil, son los países que reportan las mayores áreas productivas de higuerilla en el mundo. En un estudio reciente se realizó un análisis bioquímico de 239 genotipos de higuerilla en México, el estudio mostró una gran variación en el contenido de aceite en un rango de 25 a $66 \%$; de igual manera se encontraron 25 genotipos con contenidos superiores a $60 \%$ y se estimó que en promedio son necesarios $2 \mathrm{~kg}$ de semillas de higuerilla para obtener 1 L de aceite (Martínez-Valencia y col., 2011).

\subsubsection{Aceite usado de cocina}

Otra materia prima vegetal es el aceite usado de cocina (AUC) que proviene de un proceso de fritura de alimentos a alta temperatura $\left(160-190^{\circ} \mathrm{C}\right)$, los AUC son una de las principales fuentes de residuos ricos en nutrientes y de bajo precio de venta. Grandes cantidades de AUC se generan en los restaurantes en todo el mundo. Se ha estimado que en promedio 100 mil millones L $(\text { semana })^{-1}$ de residuos de aceite se produce en los Estados Unidos (Shah y col., 2007). Hay pocos informes que utilizan el enorme potencial de estos aceites de freír para la producción de BS (Makkar y col., 2011).

\subsubsection{Fuentes de carbono no renovables}

La mayoría de los surfactantes están hechos a base de derivados del petróleo y se sintetizan químicamente. De hecho, el petróleo ha sido el hilo conductor del desarrollo en el mundo moderno en los últimos 100 años, debido a esto el petróleo es un producto esencial para muchas industrias, y es de vital importancia para el mantenimiento de la misma civilización industrializada, por lo que se considera una industria crítica en la mayoría de las naciones (Hall y Hallock, 2003). México es un buen ejemplo de esta "regla" por lo que resulta interesante la producción de BS a partir de sustratos derivados del petróleo o del mismo petróleo. 


\subsubsection{Petróleo crudo}

El petróleo es una mezcla compleja en la que coexisten en fase sólida, liquida y gaseosa, diversos hidrocarburos y otros compuestos orgánicos constituidos además con pequeñas proporciones de compuestos como nitrógeno, azufre, oxígeno y algunos metales. El petróleo crudo es clasificado por la industria mundial de hidrocarburos líquidos de acuerdo a su gravedad específica o grado API que diferencia las calidades del crudo: (i) extraligeros (> 39 API), (ii) ligeros (31.1-39 API), (iii) medianos (22.3-31.1 API), (iv) pesados (10.22.3 API) y (v) extrapesados (<10 API). La valoración de un crudo depende de su contenido de azufre (IMP, 2011). Cuanto mayor sea el contenido de azufre menor será su precio en el mercado. Un crudo de $40^{\circ} \mathrm{API}$ tiene, por lo general, un valor mayor que un crudo de $20^{\circ} \mathrm{API}$ debido a que contiene más fracción ligera como gasolinas y menor cantidad de constituyentes pesados tales como los residuos asfalténicos. Por lo anterior los petróleos pesados se consideran de baja calidad, ya que son viscosos con densidades más altas que el agua, algunos son sólidos a temperatura ambiente y, además, ricos en azufre y metales. En México, tres tipos de crudo se producen: el Maya pesado, que constituye $52.4 \%$ del total de la producción; el Istmo-34, ligero, bajo en azufre, que representa un $35.3 \%$ de la producción; y el Olmeca-39, extra ligero, que representa un 12.4\% de la producción (PEMEX, 2012).

\subsubsection{Aceite lubricante usado}

Uno de los muchos problemas que ha surgido con el uso de derivados de hidrocarburos, son los aceites lubricantes usados (ALU). Los ALU comprenden a los aceites para motores de origen mineral que durante su uso perdieron propiedades características, volviéndose inapropiadas para continuar utilizándose con el mismo propósito. Posterior a su uso, el ALU adquiere concentraciones elevadas de hidrocarburos aromáticos, solventes clorados, junto con altas 
concentraciones de metales pesados (Benavente, 1999). Si no se dispone adecuadamente, el ALU causa problemas al ambiente: sí se arroja al suelo, destruye el humus vegetal y acaban con la fertilidad del suelo. En el agua impide la adecuada oxigenación asfixiando a los seres vivos que allí habitan. En México se estima que la generación de ALU en el periodo 2004-2011 ascendió a 192 mil toneladas de lubricantes usados (SEMARNAT, 2012) los cuales tienen un uso inadecuado, al quemarse o bien se vierten en el suelo y drenaje urbano.

\subsection{Producción de BS}

La producción de BS a gran escala y su aplicación están restringidos por los altos costos de producción y por la limitada comprensión de sus interacciones con las células y con el medio abiótico. Esto ha llevado en la última década a centrar los esfuerzos en la minimización de los costos de producción con el fin de facilitar el amplio uso comercial de los BS (Makkar y col., 2011). La aplicación de tecnologías económicas y procesos basados en la utilización de conversión de residuos a productos también está ganando terreno. Además de la materia prima, la comercialización de los BS se restringe por los altos costos de producción que pueden ser estabilizados por la optimización de las condiciones de producción y la aplicación de nuevos y eficientes pasos intermedios en los métodos de procesamiento.

\subsubsection{Biorreactores Airlift}

El uso de biorreactores Airlift (BAL) para la producción de BS no ha sido estudiada ampliamente, sólo se ha estudiado la producción del BS Surfactina de Bacillus subtilis en un BAL a partir del efluente del procesamiento de papa (Noah y col., 2002). Por lo tanto, es necesario desarrollar estudios de la factibilidad de producción de BS en BAL. Un biorreactor del tipo Airlift es un reactor agitado neumáticamente por medio del suministro de una fase 
gaseosa en la parte inferior. La fase gaseosa se expande isotérmicamente dando lugar a la formación de burbujas que ascienden hasta la parte superior de BAL, homogeneizando el contenido del reactor (Chisti, 1989). Las principales ventajas del BAL en comparación con biorreactores convencionales (tanque agitado) son la eficiencia de mezclado y las mayores tasas de aireación con un menor consumo de energía. Los BAL son utilizados en la producción de ácido láctico, degradación de compuestos fenólicos y la biodesulfuración del petróleo, entre otras aplicaciones. Sin embargo, hay escasa información disponible sobre el crecimiento de microrganismos en BAL con sustratos insolubles en agua (Lizardi-Jiménez y col., 2012) destinados para la producción de BS. Lizardi-Jiménez y Gutiérrez-Rojas en el 2011 estudiaron la hidrodinámica de BAL trifásicos, demostraron que hay una clara limitación en la transferencia de masa proveniente de la fuente de carbono particularmente cuando se trabajó con sustratos hidrofóbicos. Además, se ha demostrado que el área de transferencia específica es un parámetro que debe ser considerado en el diseño de bioprocesos de compuestos orgánicos insolubles en BAL, ya que el área de transferencia específica disminuye con el tiempo de cultivo debido a que la fuente de carbono hidrofóbica es consumida en forma emulsificada en gotas microscópicas de 0.1 a $0.7 \mu \mathrm{m}$ (Medina-Moreno y col., 2013). Por lo anterior, se propone el uso de BAL para la producción de BS a partir de fuentes de carbono insolubles en agua.

\subsection{Acinetobacter bouvetii: Productor de biosurfactante}

La mayoría de los BS descritos son de origen bacteriano y los géneros más reportados como productores de BS son Pseudomonas sp., Acinetobacter sp., Bacillus sp. y Arthrobacter sp. (Amaral y col., 2010). El BS comercial Emulsan es producido por Acinetobacter calcoaceticus RAG-1, el Alasan es producido por Acinetobacter radioresistens KA-53 y el Biodispersan es 
sintetizado por Acinetobacter radioresistens A2 (Pacwa-Plociniczak y col., 2011). Las células del género Acinetobacter se caracterizan por ser pequeñas, entre 1-1.5 y 1.5-2.5 $\mu \mathrm{m}$ durante la fase de crecimiento; en la fase estacionaria toman una forma cocoide. Todas las especias son estrictamente aerobias y estas bacterias pueden usar gran variedad de compuestos orgánicos. En el 2012, Tzintzun-Camacho y col. identificaron 4 cepas bacterianas hidrocarbonoclastas: Xanthomonas sp., Acinetobacter bouvetii, Shewanella sp. y Delfluvibacter lusatiensis. Además, demostraron que cambios en la hidrofobicidad celular y la producción de biosurfactantes por parte de A. bouvetii son prerrequisitos para la degradación de sustratos hidrófobos como el nhexadecano. Hasta el momento no se han encontrado más estudios que reporten la producción de biosurfactantes de la especie $A$. bouvetii.

\subsection{Relevancia científica y originalidad del estudio}

Un análisis realizado en ISI Web of Knowlegde (http://apps.webofknowledge.com/, 2013) a nivel mundial reveló que en los últimos 5 años la comunidad científica ha dirigido su atención al estudio de biosurfactantes. En las últimas dos décadas se han publicado 2,317 estudios relacionados con BS (Figura 2a) y el número de citas totales de estas publicaciones ascienden a 52,695 desde 1992 a la fecha (Figura 2b). En particular, el interés por los BS del género Acinetobacter se ha mantenido constante con un promedio de cuatro publicaciones al año desde 1993 a 2009 y un aumento a diez estudios anuales en los últimos tres años (Figura 2d). En total se han publicado 93 estudios de BS de Acinetobacter en los últimos 20 años con 4,403 citas totales (Figura 2e). Lo anterior confirma la relevancia científica del presente trabajo que pretende contribuir con el estudio de BS sintetizados por el género Acinetobacter. 

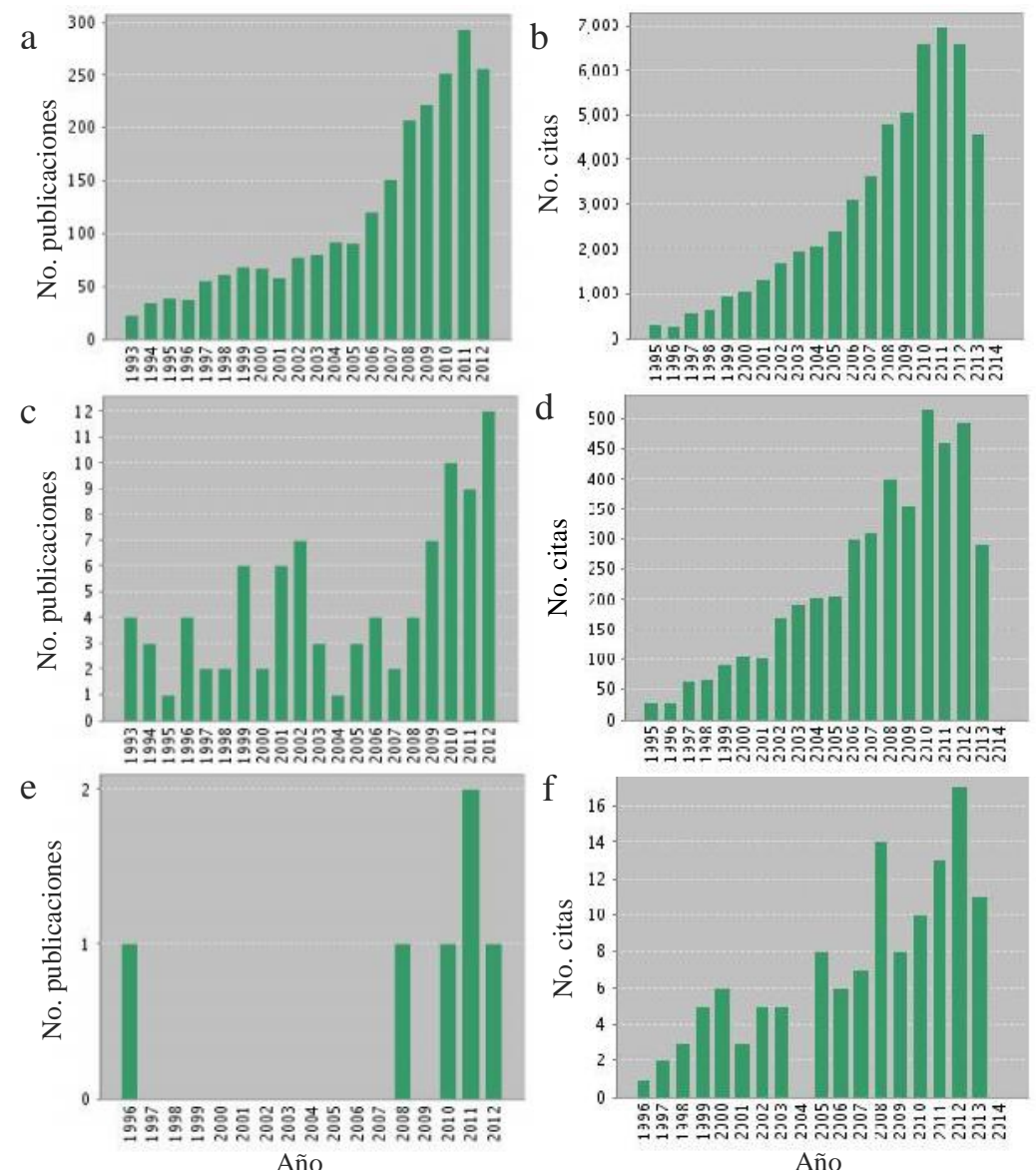

Figura 2. Reporte histórico de publicaciones científicas y número de citas por año, indexadas en Web of Science relacionadas con: biosurfactantes (a y b); biosurfactantes y Acinetobacter (c y d); biosurfactantes y Acinetobacter y fuentes de carbono hidrofóbicas (e y f).

Los estudios relacionados con el uso de fuentes de carbono hidrofóbicas para la producción de

BS de Acinetobacter son pocos (Figura 2e), seis en las últimas dos décadas con 124 citas totales

(Figura 2f). Con lo que se observa una clara ausencia de estudios sobre el tema, posiblemente debida a las dificultades biológicas y técnicas para utilizar FC hidrofóbicas. Lo que representa un interesante reto científico y tecnológico, además de denotar la originalidad de este trabajo. 


\section{Planteamiento del problema}

Recientemente, Tzintzun-Camacho y col. (2012), estudiaron los mecanismos de degradación de hexadecano utilizando consorcios bacterianos definidos, en este trabajo se demostró que la especie Acinetobacter bouvetii es capaz de producir biosurfactantes. Una de las inquietudes que surgen a raíz de este trabajo, es el estudiar la producción del o los biosurfactantes (BS) de $A$. bouvetii. En gran medida el interés se debe a que, en las últimas décadas, se ha observado un creciente interés por la producción de BS por sus aplicaciones en las industrias alimentaria, farmacéutica, petrolera y en la biorremediación de sitios contaminados con hidrocarburos. Otra inquietud que surge se centra en la búsqueda de las mejores condiciones de operación que permitan la mayor producción del BS de A. bouvetii en un biorreactor Airlift (BAL). Esto último derivado de estudios recientes (Lizardi-Jiménez y Gutiérrez-Rojas, 2011; Lizardi-Jiménez y col., 2012; Medina-Moreno y col., 2013) relacionados con la hidrodinámica de sistemas trifásicos y consumo de fuentes de carbono hidrofóbicas en BAL. Por último, resulta indispensable evaluar la posible utilización de diferentes fuentes de carbono hidrofóbicas renovables y no renovables que permitan mejorar la producción del BS de A. bouvetii. En el presente trabajo se evalúa la capacidad de cuatro fuentes de carbono hidrofóbicas: (i) aceite de higuerilla (AH); (ii) aceite usado de cocina (AUC); (iii) petróleo crudo maya (PCM) y (iv) aceite lubricante usado (ALU) para la producción del BS y su capacidad emulsificante. El trabajo se centra en aquellas posibles aplicaciones en la industria petrolera, como por ejemplo, mejorando la movilidad y solubilidad del petróleo pesado; y en la biorremediación de suelos contaminados con compuestos orgánicos hidrofóbicos. 


\section{Hipótesis}

La fuente de carbono hidrofóbica determina la eficiencia técnica y económica de la producción del biosurfactante de $A$. bouvetii.

\section{Objetivos}

Evaluar la eficiencia técnica y económica de la producción del biosurfactante de A. bouvetii a partir de diferentes fuentes de carbono hidrofóbicas a nivel de laboratorio.

\subsection{Objetivos particulares}

20 Valorar la producción de biosurfactante y el crecimiento de A. bouvetii con cuatro diferentes fuentes de carbono hidrofóbicas.

20 Estimar parámetros técnicos de crecimiento de A. bouvetii y de producción del biosurfactante obtenido a partir de fuentes de carbono hidrofóbicas.

20 Seleccionar la mejor fuente de carbono para la producción del biosurfactante de $A$. bouvetii con base en criterios de viabilidad.

20 Determinar la factibilidad técnica de la producción del biosurfactante de A. bouvetii a partir de una validación de los parámetros técnicos de crecimiento y de producción del biosurfactante.

20 Determinar la factibilidad económica de la producción del biosurfactante de A. bouvetii en función de un análisis de costos de su producción. 


\section{Estrategia de trabajo}

La estrategia experimental consistió en cuatro etapas:

I. Producción del biosurfactante (BS) de A. bouvetii a partir de distintas fuentes de carbono en botellas serológicas para la estimación de parámetros técnicos de producción de BS y crecimiento de A. bouvetii.

II. Evaluación de factibilidad técnica y selección de la mejor fuente de carbono (FC) para la producción del BS con base en criterios de viabilidad: (i) generales, (ii) económicos y (iii) tecnológicos.

III. Producción del BS de A. bouvetii en un biorreactor airlift (BAL) con la FC seleccionada para la validación de parámetros técnicos de producción y de crecimiento.

IV. Análisis de costos de producción del BS de A. bouvetii para evaluar la factibilidad económica de su producción. 


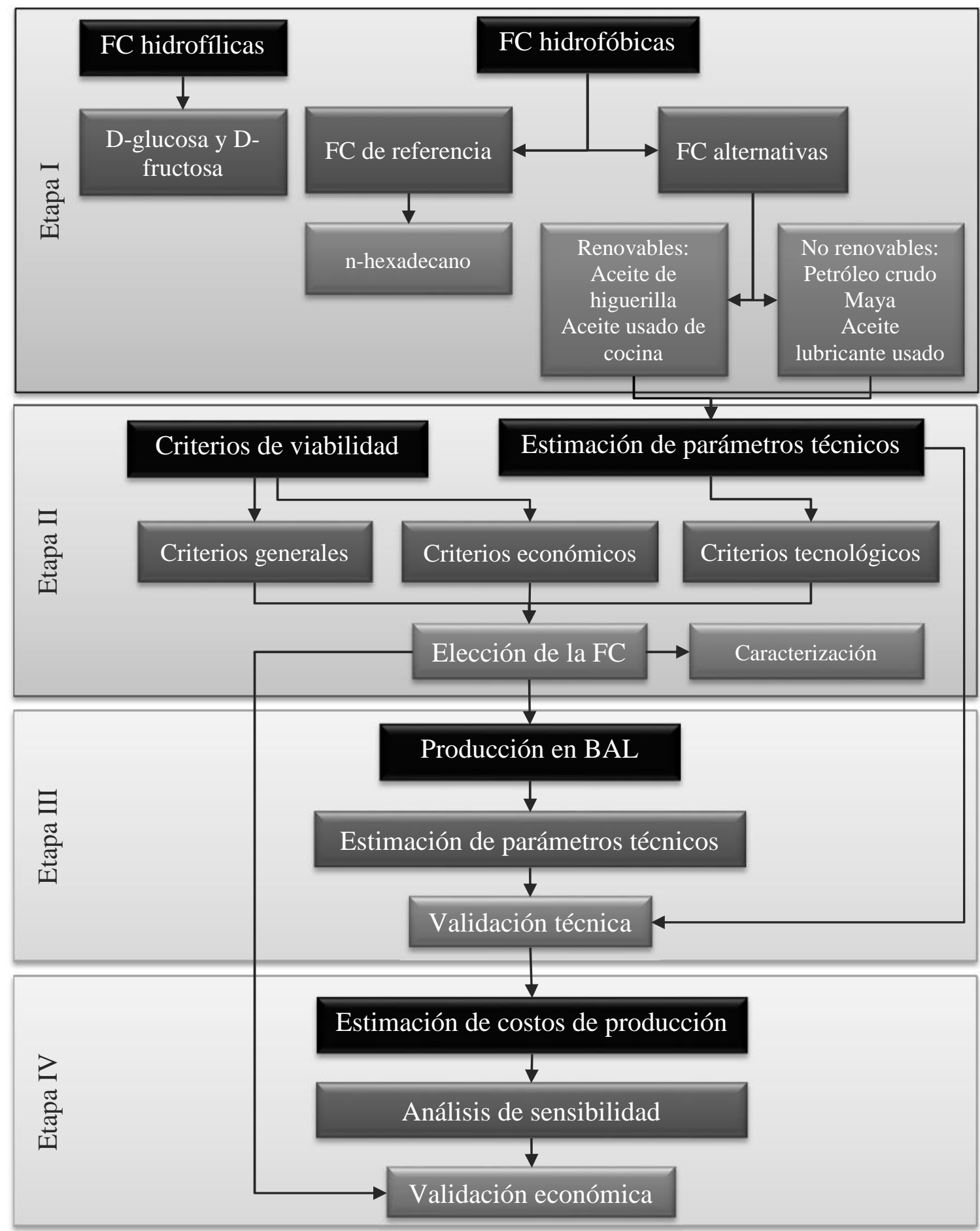

Figura 3. Estrategia experimental 


\section{Materiales y métodos}

\subsection{Material biológico y medios de cultivo}

\subsubsection{Microorganismo}

Se utilizó la bacteria Acinetobacter bouvetii (cepa UAM25). La cepa fue aislada de la rizósfera de Cyperus laxus LAM, una planta nativa de pantanos contaminados con petróleo en Veracruz, México (Díaz-Ramírez y col., 2003). A. bouvetii fue identificada mediante un análisis del gen 16s RNAr (Tzinzun-Camacho y col., 2012).

\subsubsection{Medios de cultivo}

La preservación y propagación de la cepa se realizó con Agar soya tripticaseína (TSA, Bioxon) y medio nutritivo (Bioxon). Para las cinéticas de producción del BS se utilizó medio mineral (MM) con la siguiente composición $\left(\mathrm{g} \mathrm{L}^{-1}\right)$ : 0.675 de $\mathrm{NaNO}_{3}$ (J. T. Baker, 99.9\%), 0.215 de $\mathrm{K}_{2} \mathrm{HPO}_{4}$ (J. T. Baker, 99.9\%), 0.113 de $\mathrm{KCl}$ (J. T. Baker, 99.9\%) y 0.11 de $\mathrm{MgSO}_{4} \bullet 7 \mathrm{H}_{2} \mathrm{O}(\mathrm{J} . \mathrm{T}$. Baker, 100.1\%), el MM se ajustó a un pH inicial de 6.5 con HCl 1.0 M (Medina-Moreno y col., 2005).

\subsubsection{Activación de $A$. bouvetii}

La bacteria se inoculó por picadura en matraces Erlenmeyer de $150 \mathrm{~mL}$ con $25 \mathrm{~mL}$ de caldo nutritivo. Los cultivos se incubaron a $30{ }^{\circ} \mathrm{C}$ con agitación constante de $200 \mathrm{rpm}$ en una incubadora con agitación (New Brunswick Scientific, USA) (Tzinzun-Camacho y col., 2012). Después de $24 \mathrm{~h}$ se tomaron $0.5 \mathrm{~mL}$ del cultivo, se diluyeron con agua destilada hasta un volumen final de $1.5 \mathrm{~mL}$ y se determinó la densidad óptica a $600 \mathrm{~nm}\left(\mathrm{DO}_{600}\right)$ de la dilución. La 
concentración de $A$. bouvetii $\left(\mathrm{C}_{\mathrm{Ab}}\right)$ fue determinada con una curva patrón en unidades formadoras de colonias (UFC) $\mathrm{mL}^{-1}$.

\subsection{Producción de biosurfactante a partir de distintas fuentes de carbono}

En las diferentes fuentes de carbono que se ensayaron para la producción de BS de A. bouvetii se conservó siempre una relación carbono/nitrógeno $(\mathrm{C} / \mathrm{N})$ alrededor de $10 \mathrm{~g} \mathrm{C} \mathrm{g}^{-1} \mathrm{~N}$. Las cinéticas de producción de BS se realizaron en botellas serológicas de $150 \mathrm{~mL}$ con $50 \mathrm{~mL}$ de MM inoculadas con $1 \times 10^{6} \mathrm{UFC}^{-1}$ de A. bouvetii (Tzinzun-Camacho y col., 2012).

\subsubsection{Fuentes de carbono hidrofílicas}

Las fuentes de carbono hidrofílicas utilizadas fueron D-glucosa (J. T. Baker, 99\%) y D-fructosa (J. T. Baker, $99 \%$ ). Cada fuente de carbono hidrofílica fue ensayada por separado con una concentración inicial de $2.7 \mathrm{~g} \mathrm{~L}^{-1}$. Las botellas se incubaron durante $48 \mathrm{~h}$ y se realizaron 3 réplicas.

\subsubsection{Fuentes de carbono hidrofóbicas}

Las diferentes fuentes de carbono hidrofóbicas ensayadas fueron: (i) n-hexadecano, fuente de carbono de referencia; (ii) fuentes de carbono renovables como el aceite de higuerilla (AH) y el aceite usado de cocina (AUC) y (iii) fuentes de carbono no renovables como el petróleo crudo maya (PCM) y el aceite lubricante usado (ALU).

\subsubsection{Fuente de carbono hidrofóbica de referencia}

Como fuente de carbono de referencia se utilizó n-hexadecano (Sigma Aldrich, 99.9\%) en una concentración inicial de $1.3 \mathrm{~g} \mathrm{~L}^{-1}$. Se realizaron tres réplicas por cada tiempo de cultivo analizado: 0, 6, 12, 18, 24, 30, 36, 42, 48 y $72 \mathrm{~h}$. 


\subsubsection{Fuentes de carbono hidrofóbicas renovables}

Las fuentes de carbono renovables utilizadas fueron AH (Laboratorio Productos Camacho) y AUC (muestra facilitada por el comedor de la UAM Iztapalapa) por separado en una concentración inicial de $1.11 \mathrm{~g} \mathrm{~L}^{-1}$. Se realizaron tres réplicas por cada tiempo de cultivo analizado: $0,3,6,9,12,16,20,24,36,48,72 \mathrm{~h}$.

Antes de que el AUC fuera utilizado como fuente de carbono se dejó reposar por 48 h, posteriormente el AUC se decantó y fue filtrado con papel Whatman (Grado 1). El AUC filtrado se conservó en un recipiente herméticamente cerrado de vidrio (1 L) a temperatura ambiente $(25$ $\left.{ }^{\circ} \mathrm{C}\right)$ y en oscuridad.

\subsubsection{Fuentes de carbono hidrofobicas no renovables}

Las fuentes de carbono no renovables utilizadas fueron PCM (proporcionado por el Instituto Mexicano del Petróleo) y ALU (muestra de aceite usado de motor) por separado en una concentración inicial de $1.31 \mathrm{~g} \mathrm{~L}^{-1}$. Se realizaron 3 réplicas por cada tiempo de cultivo: $0,6,12$, 15, 18, 21, 24, 30, 36, 48, 60 y 72 h. El ALU se trató y se conservó de la misma manera que el AUC antes de su utilización.

\subsection{Composición cualitativa del AUC}

La composición de ácidos grasos presentes en el AUC se determinó mediante cromatografía de gases y espectrometría de masas (CG-EM). Se determinó la acidez del AUC y enseguida se realizó una reacción de transesterificación con el AUC, a continuación se detallan las técnicas.

\subsubsection{Acidez}

Los ácidos grasos libres del AUC se determinaron en un matraz Erlenmeyer de $125 \mathrm{~mL}$, se agregó $1 \mathrm{~mL}$ de AUC, $9 \mathrm{~mL}$ de metanol y dos gotas del indicador fenolftaleína. Se tituló la 
mezcla con una solución de $\mathrm{NaOH}(0.1 \mathrm{M})$ hasta el vire del indicador. El porcentaje de acidez se calculó mediante la ecuación 6.1.

$$
\text { Acidez }=\frac{V_{\mathrm{NaOH}} * C_{\mathrm{NaOH}} * M M_{A c}}{V_{A U C} * 10}
$$

Donde $\mathrm{V}_{\mathrm{NaOH}}$ es el volumen en $\mathrm{mL}$ de solución de $\mathrm{NaOH}$ gastados en la titulación, $\mathrm{C}_{\mathrm{NaOH}}$ es la concentración molar de la solución de $\mathrm{NaOH}, \mathrm{MM}_{\text {Ác }}$ es la masa molecular del ácido graso de referencia (ácido oleico) y $\mathrm{V}_{\mathrm{AUC}}$ es el volumen en mL de AUC analizado.

\subsubsection{Reacción de transesterificación}

La reacción de transesterificación se realizó en un matraz Erlenmeyer de 125 mL con 10 mL de AUC, se adicionaron $2.44 \mathrm{~mL}$ de metanol (J. T. Baker, $99.9 \%$ ) y $100 \mathrm{mg}$ de $\mathrm{NaOH}$ finamente molido. La mezcla se mantuvo con agitación constante durante 2 h a $60{ }^{\circ} \mathrm{C}$ (Ramezani y col., 2010). Al término de la reacción, $2 \mathrm{~mL}$ de la mezcla se separaron por centrifugación (18 $500 \mathrm{~g}$, 20 min, $4{ }^{\circ} \mathrm{C}$ ), los ésteres metílicos formados fueron en un color amarillo ámbar.

\subsubsection{Cromatografía de gases y espectrometría de masas}

Los ésteres metílicos sintetizados a partir del AUC se analizaron en un cromatógrafo de gases 5890N acoplado a un detector selectivo de masas 5975B VL (Agilent Technologies). Se hizo una solución de los ésteres metílicos a una concentración de 500 mg L ${ }^{-1}$, utilizando hexano (J. T. Baker, 99.8\%) como diluyente. Un $\mu \mathrm{L}$ de esta solución fue analizado en el cromatógrafo. La separación de los ésteres se obtuvo con una columna capilar 5MS (30 m x 0.25 mm x $0.25 \mathrm{~m})$ manteniendo el flujo constante a $1 \mathrm{~mL} \mathrm{~min}^{-1}(12.75 \mathrm{psi})$. La temperatura del puerto de inyección se mantuvo a $280{ }^{\circ} \mathrm{C}$, con helio como gas acarreador. La temperatura inicial del horno fue de 
$150{ }^{\circ} \mathrm{C}$, posteriormente se elevó a $210^{\circ} \mathrm{C}$ con una rampa de $10^{\circ} \mathrm{C} \mathrm{min}^{-1}$ y por último hasta 270 ${ }^{\circ} \mathrm{C}$ con una rampa de $5{ }^{\circ} \mathrm{C} \min ^{-1}$ (Ramezani y col., 2010). La temperatura de la interfase se mantuvo a $290{ }^{\circ} \mathrm{C}$. Los resultados espectrométricos fueron obtenidos mediante el modo de adquisición SCAN, en un rango de masas de 10 a 300 UMA, con una energía de ionización de 70 eV. La identificación de ésteres metílicos se obtuvo a través de la librería NIST05a.

\subsection{Producción del BS de $A$. bouvetii en un Biorreactor Airlift}

La producción de BS a partir de AUC se realizó en un biorreactor Airlift (BAL), integrado por una columna de vidrio de $2 \mathrm{~L}$, con un diámetro externo de $0.077 \mathrm{~m}$ y un diámetro interno de $0.072 \mathrm{~m}$, un tubo concéntrico de vidrio con diámetro interno de $0.033 \mathrm{~m}$ y altura de $0.204 \mathrm{~m}$. Se utilizó un distribuidor de aire construido de acero inoxidable en forma de "L" (0.006 m de diámetro interno) con 7 perforaciones (0.001 m de diámetro y 0.004 m de separación) (LizardiJiménez y Gutiérrez-Rojas, 2011). El BAL fue operado en lote a dos velocidades superficiales de gas (Ug): 0.6 y $2.7 \mathrm{~cm} \mathrm{~s}^{-1}$ durante $72 \mathrm{~h}$ a $30^{\circ} \mathrm{C}$. Cada $\mathrm{Ug}$ se ensayó por duplicado con un volumen de operación de $1 \mathrm{~L}$, con MM, una concentración inicial de AUC de $1.11 \mathrm{~g} \mathrm{~L}^{-1}$ inoculado con $1.0 \times 10^{6} \mathrm{UFC} \mathrm{mL}^{-1}$ de $A$. bouvetii. Se tomaron $5 \mathrm{~mL}$ de muestra en los siguientes tiempos de cultivo: $0,3,6,9,12,16,20,24,30,36,42,48,60$ y $72 \mathrm{~h}$.

\subsection{Métodos Analíticos}

\subsubsection{Crecimiento bacteriano}

El crecimiento bacteriano se determinó en UFC $\mathrm{mL}^{-1}$ mediante la técnica de dilución en placa. Las diluciones correspondientes se inocularon en agar soya tripticaseína y se incubaron a $30{ }^{\circ} \mathrm{C}$. A las 48 h se realizó el conteo de las UFC. 


\subsubsection{Cuantificación del BS}

El medio de cultivo se centrifugó a 18500 g durante 20 min y $4{ }^{\circ} \mathrm{C}$, a $3 \mathrm{~mL}$ del sobrenadante se agregaron 20 L de PCM. Posteriormente la mezcla se agitó en vórtex durante 2 min, después de 24 h la fase acuosa se separó y se determinó la densidad óptica a 400 nm ( $\left.\mathrm{DO}_{400}\right)$ (Patil y Chopade, 2001). Mediante la ecuación 6.2 se determinó la concentración del BS (C BS $_{\text {) en mg }}$ equivalentes de Tween 20 por litro del sobrenadante libre de células.

$$
C_{B S}=\frac{D O_{400}+0.0321}{0.0016} \quad\left(\mathrm{R}^{2}=0.97\right)
$$

\subsubsection{Hexadecano residual}

El HXD residual se extrajo del sobrenadante libre de células $\left(50 \mathrm{~mL}, 18500 \mathrm{~g}, 4{ }^{\circ} \mathrm{C}, 20 \mathrm{~min}\right)$ con $50 \mathrm{~mL}$ de hexano:acetona 1:1 (v:v). El HXD se determinó por cromatografía de gases acoplado a un detector de ionización de flama (Star 3900, Varian). La cromatografía se realizó con una columna AT-HT (15 m x $0.25 \mathrm{~mm}$ x $0.10 \mathrm{~m}$, Heliflex) manteniendo el flujo constante a $30 \mathrm{~mL} \mathrm{~min}^{-1}(40 \mathrm{psi})$. La temperatura del puerto de inyección se mantuvo a $290{ }^{\circ} \mathrm{C}$, con helio como gas acarreador. La temperatura del horno se incrementó hasta $120{ }^{\circ} \mathrm{C}$ con una rampa de

$30{ }^{\circ} \mathrm{C} \mathrm{min}^{-1}$, posteriormente se elevó a $150{ }^{\circ} \mathrm{C}$ con una rampa de $10{ }^{\circ} \mathrm{C} \mathrm{min}^{-1}$ y por último hasta $170{ }^{\circ} \mathrm{C}$ con una rampa de $15^{\circ} \mathrm{C} \mathrm{min}^{-1}$. El detector se mantuvo a $300{ }^{\circ} \mathrm{C}$. El volumen de inyección fue de $2 \mu \mathrm{L}$ (Velasco-Alvarez y col., 2011).

\subsection{4 pH}

El pH se determinó directamente en el caldo de cultivo con un potenciómetro Oakton 1100 (Eutech Instruments, Malasia). 


\subsubsection{Tensión superficial}

La tensión superficial de los cultivos se determinó con un tensiómetro de burbuja SensaDyne QC6000 (Chem-Dyne Research Corporation, USA) a una temperatura constante de $25^{\circ} \mathrm{C}$, y utilizando como fluidos de referencia agua destilada y etanol.

\subsubsection{Potencial Z}

Se determinó el potencial Z (pZ) del sobrenadante libre de células (18 $500 \mathrm{~g}, 4{ }^{\circ} \mathrm{C}, 20 \mathrm{~min}$ ) después de 72 h de cultivo con HXD como fuente de carbono. Se tomó $1 \mathrm{~mL}$ del sobrenadante libre de células y de diluyó 1:10 con agua desionizada, se ajustó el pH a valores de 2.1, 3.1, 5.0, 7.7, 9.0 y 10.0 con $\mathrm{HCl} 0.1 \mathrm{M}$ y $\mathrm{NaOH} 0.1 \mathrm{M}$ y se determinó el potencial $\mathrm{Z}$ mediante un equipo Zetasizer nano ZS (Malvern Instruments).

\subsubsection{Actividad emulsificante}

La actividad emulsificante (AE) del extracto libre de células (18 $\left.500 \mathrm{~g}, 4{ }^{\circ} \mathrm{C}, 20 \mathrm{~min}\right) \mathrm{se}$ determinó con $0.5 \mathrm{~mL}$ del sobrenadante a los que se agregaron $7 \mathrm{~mL}$ de Tris- $\mathrm{HCl}(20 \mathrm{mM}, \mathrm{pH}$ 7) con $\mathrm{MgSO}_{4}(10 \mathrm{mM})$, enseguida se agregó 100 L de mezcla n-hexadecano:2-metilnaftaleno 1:1 (v:v) (Sar y Rosenberg, 1983). Por último, se agitó 2 min y se leyó la densidad óptica a los $3 \mathrm{~min}$ a $600 \mathrm{~nm}$. Una absorbancia de 0.1 unidades a $600 \mathrm{~nm}$ multiplicada por el factor de dilución fue considerada como una unidad emulsificante por $\mathrm{mL}\left(\mathrm{UE} \mathrm{mL}^{-1}\right)$.

\subsection{Análisis matemático}

\subsubsection{Modelo de crecimiento}

Las curvas y los parámetros de crecimiento de A. bouvetii se determinaron ajustando el modelo reparametrizado de Gompertz que se muestra en la ecuación 6.3 (Zwietering y col., 1990). 


$$
A=D e^{-e^{\left(\frac{\mu e}{D}(\lambda-t)+1\right)}}
$$

Donde A es el logaritmo natural del tamaño relativo de la población de A. bouvetii definida como $A=\ln \left(C V / C V_{t=0}\right), \mathrm{D}$ es la asíntota definida como $D=\ln \left(C V_{\infty} / C V_{t=0}\right), C V$ es la cuenta viable al tiempo $\mathrm{t}\left(\mathrm{UFC} \mathrm{mL}^{-1}\right), \quad \max$ es la tasa máxima específica de crecimiento $\left(\mathrm{h}^{-1}\right), \lambda$ es la duración de la fase lag (h).

\subsubsection{Selección de la mejor fuente de carbono hidrofóbica para la producción del BS de}

A. bouvetii

La elección de la mejor fuente de carbono hidrofóbica para ser utilizada como materia prima en la producción de BS se realizó a partir de una matriz de decisión. Fueron evaluados criterios de viabilidad con base en referencias bibliográficas y se calificaron en criterios generales, de mercado y tecnológicos que se detallan a continuación:

1) Criterios generales

a) Competencia con otros proyectos: se consideró importante debido a la utilización de la FC como materia prima en otros proyectos en México.

i) La FC no se utiliza como materia prima en otros proyectos.

ii) La FC se utiliza como materia prima en pocos proyectos.

iii) La FC se utiliza como materia prima en muchos proyectos. 
b) Se cuenta con la información suficiente: el disponer de información de la FC, como sus propiedades físicas y químicas, disminuye los riesgos que se presenten al momento de utilizarla como materia prima.

i) Información suficiente.

ii) Se cuenta con información parcial.

iii) No se cuenta con la información.

c) Beneficios adicionales de utilizar la FC: utilización de residuos, generación de subproductos o de capital.

i) Se generan beneficios adicionales.

ii) Podría generarse beneficios adicionales.

iii) No se generan beneficios adicionales.

2) Criterios de mercado

a) Existencia de incentivos fiscales: Ahorrar energía, reciclar o disminuir la producción de desechos son acciones que la industria puede intercambiar con el gobierno por descuentos en el pago de predial e impuesto sobre nómina. El uso de residuos como fuentes de carbono puede disminuir los costos de producción de BS con la obtención de incentivos fiscales.

i) $\mathrm{La} \mathrm{FC}$ es un residuo peligroso.

ii) La FC es un residuo. 
iii) La FC no es un residuo.

b) Disponibilidad de la fuente de carbono: es importante que la FC esté disponible en el Estado donde se encuentre la planta de producción del BS para evitar costos de transporte.

i) Existen proveedores de la FC.

ii) No existen proveedores pero es fácil disponer de la FC.

iii) No existen proveedores y es difícil disponer de la FC.

c) Costo de la fuente de carbono: precio de venta de la FC.

i) Menor o igual a $0.50 \mathrm{USD} \mathrm{kg}^{-1}$ de FC.

ii) Mayor a 0.50 y menor o igual a $1 \mathrm{USD} \mathrm{kg}^{-1} \mathrm{de}$ FC.

iii) Mayor a $1 \mathrm{USD} \mathrm{kg}^{-1}$ de FC.

d) Pretratamiento: fue valioso considerar si es necesario un tratamiento de la FC antes de entrar al proceso de producción.

i) No es necesario un pretratamiento.

ii) Es necesario un pretratamiento simple.

iii) Es necesario un pretratamiento complejo.

3) Criterios tecnológicos 
a) Infraestructura tecnológica: la tecnología necesaria debe existir y estar al alcance para pretratar y procesar la FC.

i) Altamente disponible.

ii) Disponible.

iii) Poco disponible.

b) Tasa especifica máxima de crecimiento $\left(\boldsymbol{\mu}_{\max }\right)$ : la $\mu_{\max }$ expresa la rapidez con que $A$. bouvetii asimila la fuente de carbono para su crecimiento.

i) $\mu_{\max }$ mayor a la estimada con la $\mathrm{FC}$ de referencia.

ii) $\mu_{\max }$ igual a la estimada con la FC de referencia.

iii) $\mu_{\max }$ menor a la estimada con la FC de referencia.

c) Duración de la fase lag ( $\lambda$ ): la $\lambda$ es el periodo de tiempo durante el que A. bouvetii se adapta a la fuente de carbono.

i) $\lambda$ menor a la estimada con la FC de referencia.

ii) $\lambda$ igual a la estimada con la FC de referencia.

iii) $\lambda$ mayor a la estimada con la FC de referencia.

d) Concentración máxima ( $\left.\mathbf{X}_{\mathbf{m a x}}\right)$ : la $\mathbf{X}_{\max }$ es la cantidad máxima de crecimiento de $A$. bouvetii.

i) $\mathrm{X}_{\max }$ mayor a la determinada con la $\mathrm{FC}$ de referencia. 
ii) $\mathrm{X}_{\max }$ igual a la determinada con la FC de referencia.

iii) $X_{\max }$ menor a la determinada con la FC de referencia.

e) Actividad emulsificante (AE): la AE es una medida de la capacidad emulsificante del BS producido a partir de la fuente de carbono.

i) AE mayor a la determinada con la FC de referencia.

ii) AE igual a la determinada con la FC de referencia.

iii) $\mathrm{AE}$ menor a la determinada con la $\mathrm{FC}$ de referencia.

Los criterios se ponderaron de acuerdo a su relevancia y cada FC se clasificó en i, ii o iii conforme a sus características, la clasificación i recibió una valoración de 1 punto, ii de 0.5 puntos y iii de 0 puntos. La calificación de cada criterio se obtuvo multiplicando la ponderación del criterio por su valoración. Finalmente, la calificación de la FC se obtuvo sumando las calificaciones de todos los criterios.

\subsubsection{Modelo de producción exponencial máximo}

Las curvas y los parámetros de producción del BS se determinaron ajustando el modelo de producción exponencial máximo (Motulsky y Ransnas, 1987) que se muestra en la ecuación 6.4

$$
P=P_{\max }\left(1-e^{-v * t}\right)
$$

Donde P es el logaritmo natural de la actividad emulsificante relativa del BS definida como $P=\ln \left(A E / A E_{t=0}\right), P_{\max }$ es el cambio máximo de actividad emulsificante definido como 
$P_{\max }=\ln \left(A E_{\infty} / A E_{t=0}\right)$, AE es la actividad emulsificante al tiempo t, $v$ es la tasa máxima de AE $\left(h^{-1}\right)$ y $t$ es el tiempo (h).

\subsubsection{Estimación del costo de producción de biosurfactante}

La estimación del costo de producción de BS se determinó en función de cuatro parámetros centrales: (i) la concentración inicial de la fuente de carbono (FC), (ii) el precio de venta comercial de la FC, (iii) la concentración final de BS y (iv) el costo de purificación. El costo de producción de BS se puede calcular mediante la ecuación general 6.5.

\section{Costo de BS = Costo de materias primas + Costo de operación}

El costo total de las materias primas se calculó con la siguiente expresión:

$$
\text { Costo de materias primas }=\text { Costo de } M M+\text { Costo de FC }
$$

El costo del medio mineral (MM) se determinó en 0.0353 dólares estadounidenses (USD) L ${ }^{-1}$ con base en precios de venta de sales minerales y la formulación empleada en este trabajo. El precio de venta de las FC se cotizó directamente con los proveedores, los valores, expresados en USD kg- ${ }^{1}$, fueron los siguientes: AH en 8.19, el AUC en 0.03, el PCM en 0.88 y el ALU en 0.65. El costo de la FC por L de medio de cultivo se expresó en función de la concentración inicial de FC, como sigue:

$$
\text { Costo de } F C=C_{F C} S_{F C}
$$

Donde $\mathrm{C}_{\mathrm{FC}}$ es la concentración inicial de FC en kg L ${ }^{-1}$ de MM y $\mathrm{S}_{\mathrm{FC}}$ es el precio en $\mathrm{USD} \mathrm{kg}^{-1}$ de FC. Por lo anterior, la ecuación 6.6 se denotó como sigue: 


$$
\text { Costo de materias primas }=0.0353+C_{F C} S_{F C}
$$

Los costos de operación generados por mano de obra, operación de equipos y consumo de servicios (gas, agua y energía eléctrica, entre otros) pueden representar de un $70 \%$ hasta un 90 $\%$ del costo total de producción del BS (Cameotra y Makkar, 1998). Por lo tanto, el costo de operación se estimó con la ecuación 6.9.

$$
\frac{\text { Costo de operación }}{\text { Costo de } B S}=0.7
$$

Al sustituir las expresiones 6.8 y 6.9 en la ecuación 6.5, se obtuvo:

$$
\text { Costo de } B S=\frac{0.0353+C_{F C} S_{F C}}{0.3}
$$

Posteriormente para estimar de manera más completa los costos de producción del BS, fue necesario considerar el costo generado por un proceso de purificación. De hecho, los costos generados por la purificación de BS pueden representar hasta un $60 \%$ del costo total de producción (Desai y Banat, 1997). Por lo anterior, el costo total de producción del BS se calculó mediante la ecuación 6.11 y el costo de purificación de BS se consideró como una fracción del costo total de producción de BS (Ec. 6.12).

Costo total de producción de BS = Costo de BS + Costo de purificación (6.11)

$$
S_{P}=\frac{\text { Costo de purificación }}{\text { Costo total de producción de BS }}
$$


Donde $\mathrm{S}_{\mathrm{P}}$ es la fracción del costo total de producción de BS debida a un proceso de purificación, la cual puede variar entre 0 y 0.6. Al sustituir las ecuaciones 6.10 y 6.12 en la expresión 6.11, se obtuvo:

$$
\text { Costo total de producción de } B S=\frac{0.0353+C_{F C} S_{F C}}{0.3 *\left(1-S_{P}\right)}
$$

Por último, se definió la ecuación 6.14 para expresar el costo de BS en USD kg-1 utilizando como factor de conversión la concentración final de BS.

$$
\text { Costo total de producción de } B S=S_{B S} C_{B S}
$$

Donde $\mathrm{S}_{\mathrm{BS}}$ es el costo en USD kg${ }^{-1}$ de $\mathrm{BS}$ y $\mathrm{C}_{\mathrm{BS}}$ es la concentración final de $\mathrm{BS}$ en $\mathrm{kg} \mathrm{L}^{-1}$ de MM. Al igualar las ecuaciones 6.13 y 6.14 se obtuvo la ecuación 6.15 que se utilizó para estimar el costo de $\mathrm{BS}\left(\mathrm{S}_{\mathrm{BS}}\right)$ en función de $\mathrm{C}_{\mathrm{FC}}, \mathrm{S}_{\mathrm{FC}}, \mathrm{C}_{\mathrm{BS}}$ y $\mathrm{S}_{\mathrm{P}}$.

$$
S_{B S}=\frac{0.0353+C_{F C} S_{F C}}{0.3 * C_{B S}\left(1-S_{P}\right)}
$$

\subsection{Análisis estadístico}

Para el ajuste no lineal de los modelos reparametrizado de Gompertz y producción exponencial máximo, se utilizó el método de estimación de Levenberg-Maquard con el software SPSS v. 18.0 (SPSS Inc., 2009). El software SigmaPlot 12.5 (Systat Software Inc, 2011) se utilizó para el análisis de varianza (ANOVA), prueba Tukey y prueba t con $\alpha$ igual a 0.05 . 


\section{Resultados y discusión}

\subsection{Producción del biosurfactante de $A$. bouvetii a partir de distintas fuentes de carbono}

Los miembros del género Acinetobacter son quimioheterótrofos que utilizan una gran variedad de sustratos como únicas fuentes de carbono y energía (Doughari y col., 2011), recientes reportes han utilizado etanol (Su y col., 2009), glucosa (Amoabediny y col. 2010) y hexadecano (Chen y col., 2012) en la producción de los biosurfactantes del género. Por lo tanto, para la producción del BS de A. bouvetii se probaron fuentes de carbono tanto hidrofílicas como hidrofóbicas.

\subsubsection{Fuentes de carbono hidrofílicas}

Se ensayó con D-glucosa y D-fructosa como fuentes de carbono hidrofílicas para la producción de BS. Nuestra cepa de A. bouvetii no fue capaz de asimilar ninguno de los dos sustratos. Lo anterior concuerda con lo reportado para Acinetobacter sp. YC-X2 (Chen y col., 2012) y otras especies de Acinetobacter (Baumann y col., 1968; Warskow y Juni, 1972; Navon-Venezia y col., 1995). La incapacidad de A. bouvetii para crecer con glucosa o fructosa como única fuente de carbono se puede deber a la ausencia de una enzima clave para la asimilación de estos sustratos (Juni, 1978). Se ha demostrado que el género Acinetobacter degrada glucosa exclusivamente por la vía Entner-Doudoroff, donde la glucosa-6-fosfato se oxida a 6fosfogluconato por acción de la enzima glucosa deshidrogenasa (Bouvet y Bouvet, 1989) y posteriormente el 6-fosfogluconato se oxida a 2-ceto-3-desoxi-6-fosfogluconato mediante la enzima gluconato deshidrogenasa. Esta última enzima está ausente en algunas especies del 
género Acinetobacter provocando una acumulación de 6-fosfogluconato y su incapacidad para asimilar glucosa como única fuente de carbono (Juni, 1978).

\subsubsection{Fuente de carbono hidrofóbica de referencia}

El n-hexadecano (HXD) es un alcano que se ha empleado como única fuente de carbono en estudios del género Acinetobacter (Ishige y col., 2000; Phetrong y col., 2008; Chen y col., 2012,). Además, la experiencia adquirida por nuestro grupo de trabajo hizo del HXD la FC de referencia para la producción del BS de A. bouvetii. En los apartados que siguen se muestran el crecimiento de A. bouvetii, consumo de HXD, producción de BS, tensión superficial pH y potencial Z.

\subsubsection{Crecimiento de A. bouvetii, consumo de HXD y producción de BS}

En la Figura 4 se presenta la producción de BS (eje vertical izquierdo), el crecimiento de $A$. bouvetii (primer eje vertical derecho) y la concentración de HXD residual (segundo eje vertical derecho) con respecto el tiempo de cultivo. A. bouvetii creció a partir de una concentración inicial de $8.72 \pm 0.53 \times 10^{5} \mathrm{UFC} \mathrm{mL}^{-1}$ hasta una concentración de $1.25 \pm 0.24 \times 10^{8} \mathrm{UFC} \mathrm{mL}^{-1}$. Tzintzun-Camacho y col. (2012) reportaron un crecimiento aproximadamente 10 veces mayor de $A$. bouvetii $\left(1.3 \pm 0.04 \times 10^{9} \mathrm{UFC}^{-1}\right)$ con una concentración de $\mathrm{HXD}$ y medio mineral 10 veces mayor al utilizado en este estudio. Durante la cinética se consumieron $805 \pm 33 \mathrm{mg} \mathrm{L}^{-1}$ de HXD en $30 \mathrm{~h}$, es decir el 61.9 $\pm 1.7 \%$ del HXD inicial, resultado menor al reportado por TzintzunCamacho y col. en el 2012 (72 $\pm 4 \%$ en 360 h) con una concentración inicial de HXD 10 veces mayor (13 $\left.000 \mathrm{mg} \mathrm{L}^{-1}\right)$. Sin embargo, las tasas promedio de consumo de HXD fueron iguales en ambos estudios (26. 8 y $26 \mathrm{mg} \mathrm{HXD} \mathrm{h}^{-1}$ ) lo que sugiere que la concentración inicial de HXD no tuvo un efecto sobre la tasa de consumo. Esto se explica por un consumo de HXD a través 
del contacto directo entre las células de $A$. bouvetii y gotas de HXD. Se ha demostrado que el mecanismo de consumo de FC hidrofóbicas por especies del género Acinetobacter es mediante contacto directo (Baldi y col., 1999; Hori y col., 2002; Baldi y col., 2003; Bihari y col., 2007).

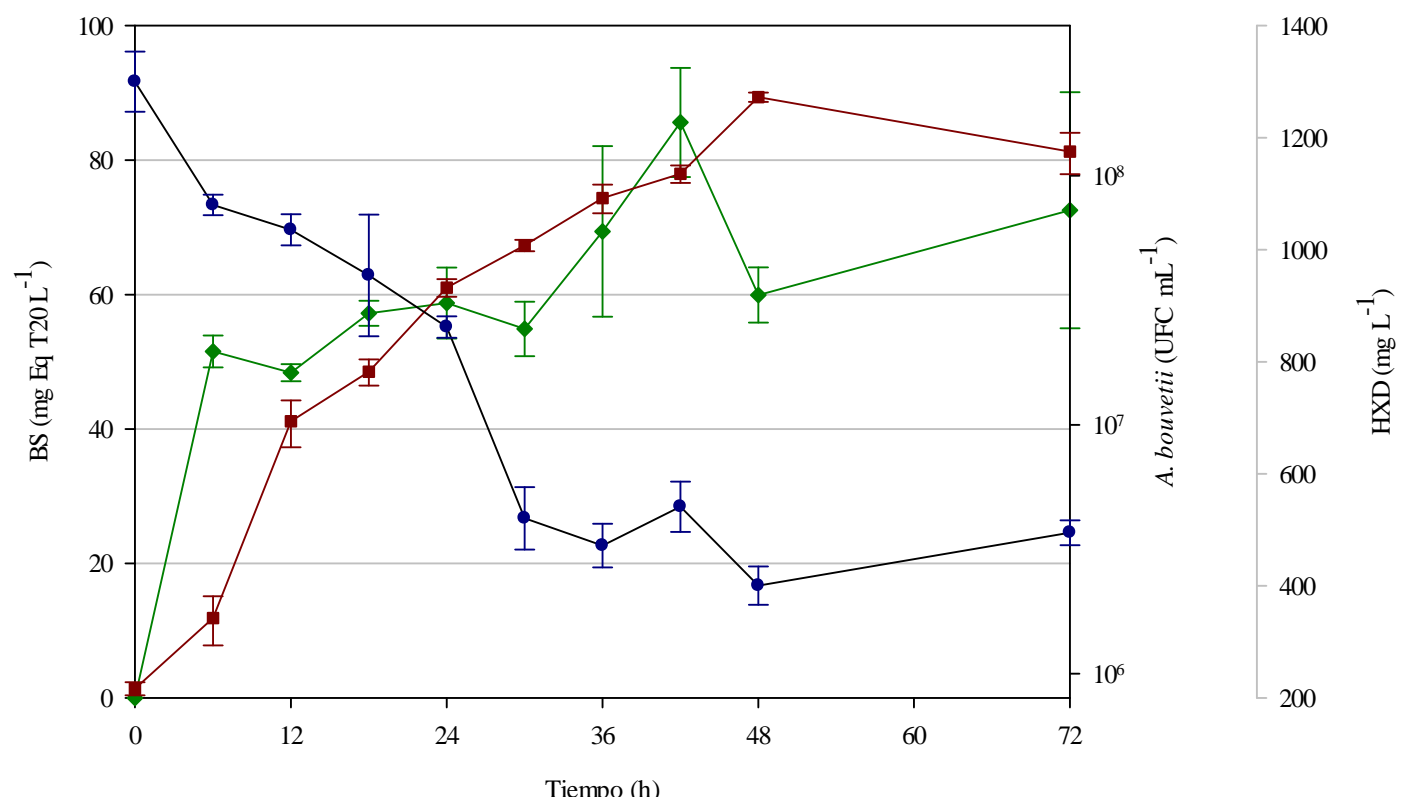

Figura 4. Cinética de producción del BS ( $\diamond)$, crecimiento de $A$. bouvetii $(\square)$ y consumo de n-hexadecano (•). Cada punto representa el valor promedio de tres repeticiones y las barras el error estándar.

En el caso de la producción del BS por A. bouvetii se observó un máximo de producción de $86 \pm 8 \mathrm{mg}$ eq T20 L ${ }^{-1}$ a las $42 \mathrm{~h}$ de cultivo. Tzintzun-Camacho y col. (2012) reportaron una concentración de 170 mg eq T20 L L de BS después de 120 h de cultivo, cerca del doble de concentración de BS cuantificado en este trabajo pero a una concentración inicial de nutrientes 10 veces mayor. Es importante destacar que la producción de BS estuvo parcialmente ligada al crecimiento de $A$. bouvetii, observación similar a lo reportado para el BS de Acinetobacter sp. YC-X 2 (Chen y col., 2012) y el BS de A. lwoffii TA38 (Jagtap y col., 2010).

La cuantificación del BS de $A$. bouvetii en unidades equivalentes de Tween $20 \mathrm{~L}^{-1}$ fue un método sencillo y rápido que facilitó la cuantificación del BS, además de poder comparar los resultados 
con antecedentes directos. Sin embargo, no fue posible comparar estos resultados con los reportados por otros grupos de trabajo debido a que la cuantificación de la actividad emulsificante de los BS producidos por especies del género Acinetobacter se determina tradicionalmente por un método estándar (ver sección 6.5.7) (Sar y Rosenberg, 1983), por lo que se decidió cambiar de método. La actividad emulsificante (EA) del BS producido con HXD

fue de $5.18 \mathrm{UE} \mathrm{mL}^{-1}$ después de $72 \mathrm{~h}$ de cultivo, actividad menor a la reportada para el BS de A. calcoaceticus RAG-1 (Emulsan) que fue de $12.67 \mathrm{UE} \mathrm{mL}^{-1}$ producido con $\mathrm{HXD}$ como principal FC (Rosenberg y col., 1979b). Además de estudiar la producción del BS a partir de HXD, se evaluó la capacidad del BS de A. bouvetii como agente tensoactivo.

\subsubsection{Tensión superficial}

Con el objetivo de estudiar la capacidad de modificar la tensión superficial del BS de A. bouvetii, se determinó la tensión superficial del medio de cultivo durante una cinética de producción (Figura 5). La tensión superficial aumentó de $71.8 \pm 0.1 \mathrm{mN} \mathrm{m}^{-1}$ hasta un máximo $72.7 \pm 0.1 \mathrm{mN}$ $\mathrm{m}^{-1}$ a las $72 \mathrm{~h}$ de cultivo, un resultado importante por dos razones: (i) las especies de Acinetobacter producen biosurfactantes de alto peso molecular y se clasifican como bioemulsificantes (Phetrong y col., 2008) y (ii) los bioemulsificantes están compuestos por mezclas de polímeros de carácter hidrofóbico e hidrofílico que pueden llegar a aumentar la tensión superficial (Franzetti y col., 2010). Debido a lo anterior, el BS de A. bouvetii es un bioemulsificante que incrementa la tensión superficial del medio de cultivo. El bioemulsificante Alasan de A. radioresistens KA53 es un complejo aniónico de alto peso molecular conformado por polisacáridos y proteínas (Navon-Venezia y col., 1995), en ese estudio se menciona un incremento del pH del medio de cultivo paralelo al crecimiento y producción del emulsificante 
producido por la cepa KA53. Por lo anterior, se realizó una valoración de pH en el medio de cultivo durante la cinetica de producción del BS de A. bouvetii.

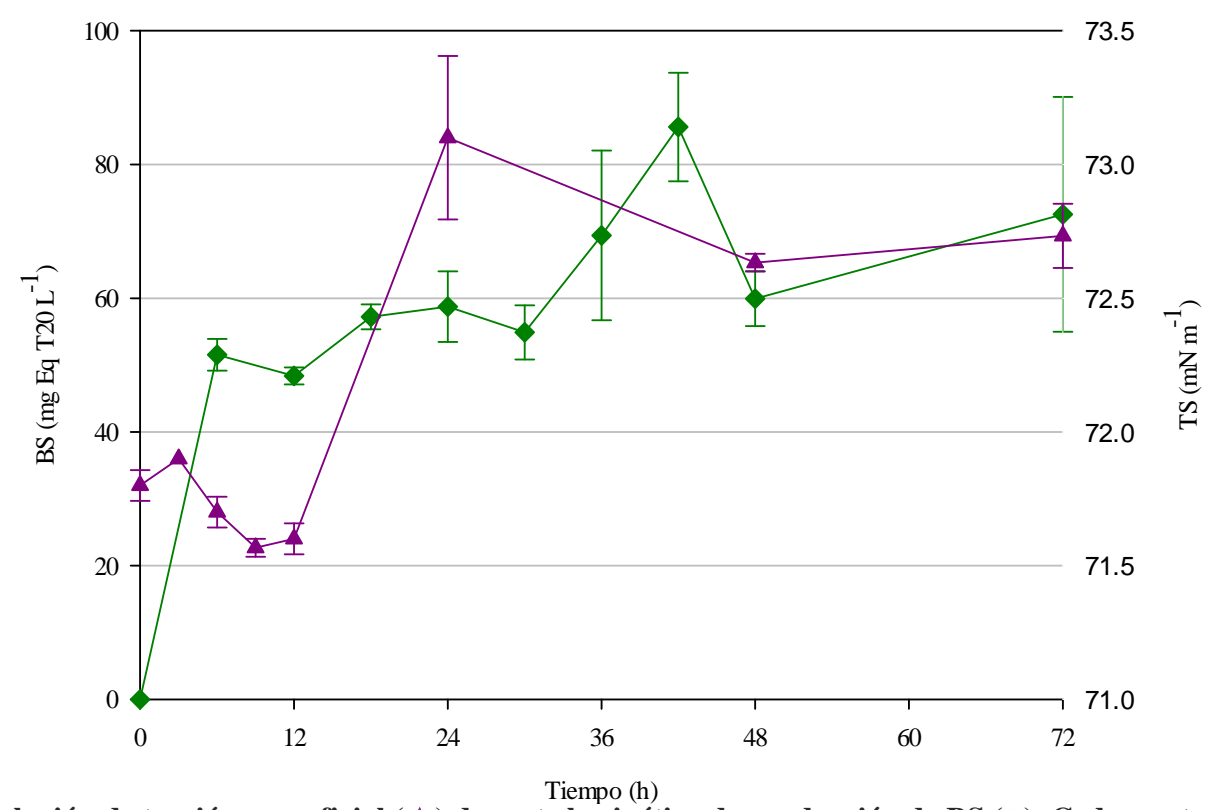

Figura 5. Evolución de tensión superficial $(\Delta)$ durante la cinética de producción de BS $(\diamond)$. Cada punto representa el valor promedio de tres repeticiones y las barras el error estándar.

\subsubsection{3 pH y potencial Z}

El pH del medio de cultivo se determinó durante la cinética de producción de BS por A. bouvetii.

En la Figura 6 se observa la evolución del pH (eje vertical izquierdo) a lo largo del tiempo de

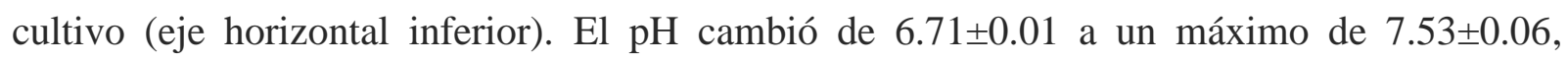
resultado que sugiere un posible carácter aniónico del BS de A. bouvetii. Para confirmar el posible carácter aniónico del BS de A. bouvetii se determinó el potencial Z (pZ) del sobrenadante libre de células después de 48 h de cultivo. En la Figura 6 se muestra el pZ (eje vertical izquierdo) a diferentes valores de $\mathrm{pH}$ (eje horizontal superior). El pZ es una medida de la magnitud de la repulsión o atracción entre las partículas y en las condiciones ensayadas, el pZ tiene una aproximación aceptable al potencial de superficie. En todos los pH ensayados el pZ 
siempre fue negativo con valores entre $-7.5 \mathrm{mV}(\mathrm{pH}=2.1)$ y $-36.7 \mathrm{mV}(\mathrm{pH}=10.0)$, lo que confirmo el carácter aniónico del BS de A. bouvetii.

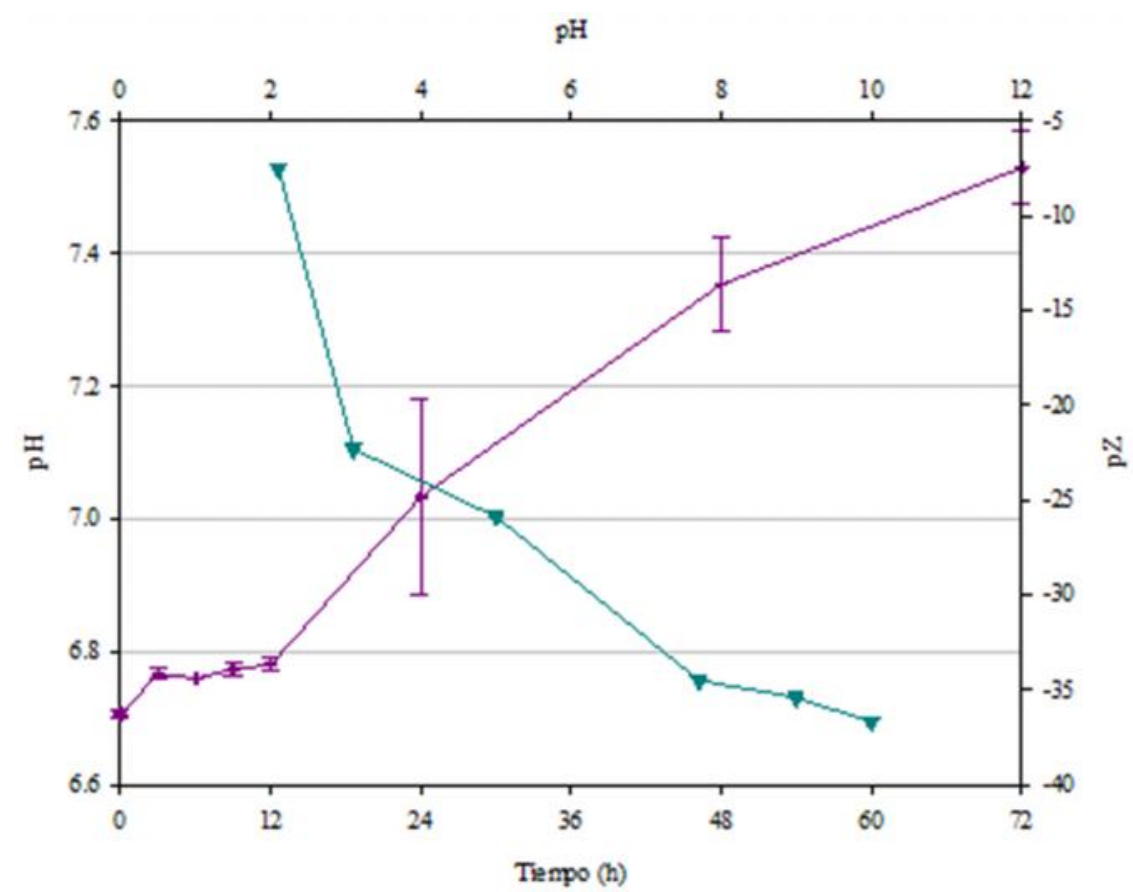

Figura 6. Evolución del pH (+) durante la cinética de producción de BS y Potencial Z ( $\nabla$ ) del sobrenadante libre de células (48 h de cultivo) a diferentes $\mathrm{pH}$.

Con base en los resultados anteriores, se puede describir de manera preeliminar al BS de $A$. bouvetii como un bioemulsificante con carácter aniónico, descripción similar al Alasan producido por A. radioresistens (Navon-Venezia y col., 1995); sin embargo, es necesaria una purificación y caracterización molecular para describir con más detalle el BS de A. bouvetii. De hecho, nuestros resultados preliminares sugieren que se podría mejorar la purificación del BS al utilizar un coagulante catiónico que favorezca la precipitación del BS o utilizar un proceso de separación basado en un intercambio iónico. En esto radica la importancia de nuestras observaciones con el potencial Z. 
La producción del BS de A. bouvetii con HXD fue crucial para: (i) la selección de métodos de evaluación, (ii) tratamiento de unidades experimentales, (iii) propiedades del BS y contar con una FC de referencia. Sin embargo, uno de los objetivos de este estudio fue proponer fuentes de carbono hidrofóbicas para la producción del BS, punto que se aborda a continuación.

\subsubsection{Fuentes de carbono hidrofóbicas}

Hay numerosas aplicaciones de las especies de Acinetobacter: (i) en el tratamiento de residuos peligrosos tales como bifenilo, fenol, petróleo crudo, acetonitrilo, eliminación de fosfato y de metales pesados o (ii) como productores de compuestos de importancia económica como lipasas, proteasas y bioemulsificantes (Abdel-El-Haleem, 2003). Por lo anterior, para la presente investigación se consideraron ciertos residuos como fuentes de carbono hidrofóbicas para la producción de BS por A. bouvetii, dos fuentes de carbono hidrofóbicas con carácter renovable, se utilizaron: (i) aceite de Higuerilla o ricino (AH) y (ii) aceite usado de cocina (AUC), también dos de carácter no renovable: (i) petróleo crudo Maya (PCM) y (ii) aceite lubricante usado (ALU).

\subsubsection{Crecimiento de A. bouvetii en fuentes de carbono hidrofóbicas}

Las cinéticas de crecimiento de A. bouvetii con las diferentes fuentes de carbono hidrofóbicas se muestra en la Figura 7. A. bouvetii fue capaz de asimilar todas las fuentes de carbono hidrofóbicas que se ensayaron; de hecho, las mejores fuentes de carbono para el crecimiento de A. bouvetii fueron el AH y AUC sin diferencias significativas $(p<0.05)$ entre las concentraciones finales de $A$. bouvetii después de $72 \mathrm{~h}$ de cultivo y sus promedios fueron de $1.71 \pm 0.36 \mathrm{x} 10^{9} \mathrm{y}$ $1.82 \pm 0.07 \times 10^{9} \mathrm{UFC} \mathrm{mL}^{-1}$, respectivamente. Las concentraciones finales de A. bouvetii con HXD, PCM y ALU no fueron diferentes significativamente $(\mathrm{p}<0.05)$ y sus medias fueron 
$0.14 \pm 0.02 \times 10^{9}, 0.18 \pm 0.01 \times 10^{9}$ y $0.19 \pm 0.03 \times 10^{9} \mathrm{UFC} \mathrm{mL}^{-1}$, respectivamente. Las diferencias en el crecimiento de $A$. bouvetii se podrían explicar por la riqueza de compuestos presentes en los aceites vegetales que son compuestos más simples y parcialmente oxidados (Makkar y col., 2011) en comparación con los compuestos presentes en el PCM y ALU. La capacidad para degradar aceites vegetales y aceites usados de cocina por especies del género Acinetobacter ha sido demostrada (Abdel-El-Haleem, 2003; Tanaka y col., 2010; Pirog y col., 2013;). Esta capacidad, la determina la producción de una lipasa extracelular definida como LipA (Snellman, 2002; Tanaka y col. 2010) que cataliza la hidrólisis de triglicéridos para producir ácidos grasos libres y glicerol. Cabe destacar que las lipasas constituyen el grupo de enzimas de mayor importancia debido a su potencial aplicación biotecnológica en biocatálisis (Jaeger, 2002; Hasan, 2006).

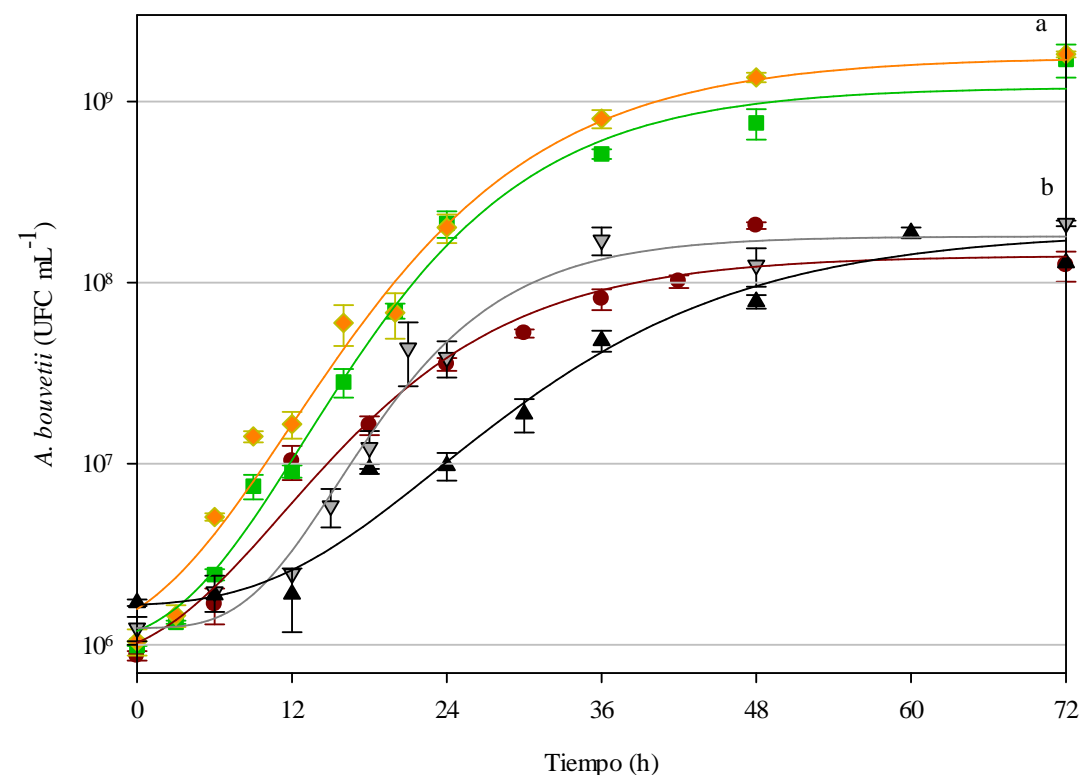

Figura 7. Cinéticas de crecimiento de $A$. bouvetii y curvas ajustadas con el modelo de Gompertz. AH ( ), AUC ( ), HXD (•), PCM ( ) ALU ( $\nabla$ ). Cada punto representa el valor promedio de tres repeticiones y el error estándar. Letras diferentes indican diferencias significativas $(\alpha=0.05$, prueba Tukey).

Para describir las curvas de crecimiento de A. bouvetii y para reducir los datos experimentales a un número limitado de parámetros técnicos de interés ( $\mu_{\max }, \lambda$ y $\left.\mathrm{D}\right)$, fue necesario utilizar un 
modelo adecuado. El modelo de Gompertz se limita a describir el número de organismos y no incluye el consumo de sustrato (Gompertz, 1825) como lo haría un modelo basado en la ecuación de Monod, por lo que se ajustó el modelo reparametrizado de Gompertz a los datos experimentales (ver ecuación 6.3 y Figura 7) con el objetivo de comparar parámetros cinéticos de crecimiento de $A$. bouvetii. Los modelos ajustados representaron al menos el $98 \%$ de la variación de los datos experimentales $\left(\mathrm{R}^{2} \searrow 0.98\right)$, es decir, con el modelo de Gompertz fue posible describir el crecimiento de A. bouvetii utilizando FC hidrofóbicas como el AH, AUC, ALU y PCM, además de obtener los parámetros técnicos de crecimiento necesarios para seleccionar la mejor de las FC hidrofóbicas.

\subsubsection{Estimación de parámetros cinéticos de crecimiento de A. bouvetii}

En la Tabla 1 se enlistan los parámetros cinéticos estimados para las distintas fuentes hidrofóbicas de carbono. Con las fuentes de carbono AH, AUC y ALU se observaron las mejores tasas máximas específicas de crecimiento $\left(\mu_{\max }\right) \quad 0.26 \pm 0.01,0.24 \pm 0.02$ y $0.25 \pm 0.03 \mathrm{~h}^{-1}$, respectivamente.

Tabla 1. Parámetros cinéticos de crecimiento de $A$. bouvetii estimados con el modelo de Gompertz.

\begin{tabular}{|c|c|c|c|c|c|c|c|}
\hline \multirow{2}{*}{ Fuente de carbono } & \multicolumn{2}{|c|}{$\mu_{\max }$} & \multicolumn{2}{|c|}{$\lambda$} & \multicolumn{2}{|c|}{$\mathrm{D}$} & \multirow{2}{*}{$\begin{array}{c}\mathrm{X}_{\max } \\
\text { UFC mL } \mathrm{mL}^{-1}\end{array}$} \\
\hline & $\mathrm{h}^{-1}$ & ES & $\mathrm{h}$ & ES & & ES & \\
\hline Aceite de Higuerilla & $0.26^{\mathrm{a}}$ & 0.01 & $2.95^{b}$ & 0.61 & $7.09^{2}$ & 0.14 & $1.71 \times 10^{9 a}$ \\
\hline Aceite Usado de Cocina & $0.24^{\text {abc }}$ & 0.02 & $0.71^{b}$ & 0.83 & $7.43^{\mathrm{a}}$ & 0.19 & $1.82 \times 10^{9 a}$ \\
\hline Petróleo crudo maya & $0.13^{d}$ & 0.01 & $10.04^{\mathrm{a}}$ & 1.81 & $4.77^{\mathrm{b}}$ & 0.24 & $0.19 \times 10^{9 b}$ \\
\hline Aceite Lubricante Usado & $0.25^{\mathrm{ab}}$ & 0.03 & $8.24^{\mathrm{a}}$ & 1.43 & $4.98^{\mathrm{b}}$ & 0.19 & $0.18 \times 10^{9 b}$ \\
\hline n-Hexadecano & $0.19^{\text {bcd }}$ & 0.02 & $1.12^{b}$ & 1.21 & $5.17^{\mathrm{b}}$ & 0.14 & $0.14 \times 10^{9 b}$ \\
\hline
\end{tabular}

*ES es el error estándar de la estimación.

Las $\mu_{\max }$ más bajas de $A$. bouvetii se observaron con $\operatorname{HXD}\left(0.19 \pm 0.02 \mathrm{~h}^{-1}\right)$ y PCM $\left(0.13 \pm 0.01 \mathrm{~h}^{-}\right.$

$\left.{ }^{1}\right)$. Lo anterior se puede explicar por la composición de las fuentes de carbono; el ALU, el AUC 
y el AH contienen compuestos parcialmente oxidados (Dominguez-Rosado y col., 2003;

Knothe y Steidley, 2009; Mohamed y col., 2010) que pueden ser fácilmente asimilados, en cambio el HXD es un compuesto totalmente reducido y el PCM una mezcla de compuestos complejos y reducidos en su mayoría (Cañipa-Morales y col., 2003) que son difíciles de asimilar. Los mayores cambios en la densidad poblacional (D) de A. bouvetii se observaron con AH (7.1 \pm 0.14$)$ y AUC $(7.43 \pm 0.19)$ lo que finalmente demostró que $A$. bouvetii creció con mayor facilidad en las FC hidrofóbicas de carácter renovables.

\subsubsection{Actividad emulsificante del biosurfactante de A. bouvetii producido a partir de distintas fuentes de carbono hidrofóbicas}

Para valorar la capacidad emulsificante del BS de A. bouvetii producido a partir de distintas fuentes de carbono se determinó la actividad emulsificante (AE) del BS a lo largo de las cinéticas de crecimiento como se muestra en la Figura 8.

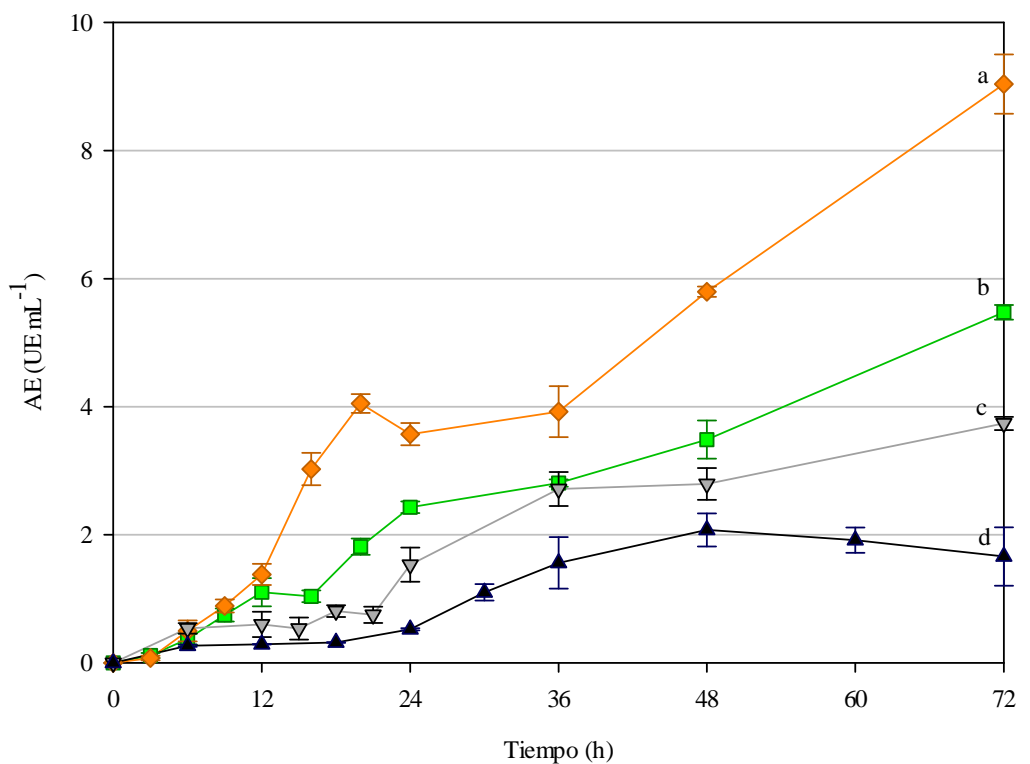

Figura 8. Actividad emulsificante del BS de A. bouvetii producido a partir de distintas fuentes de carbono. AH ( ), AUC ( ), PCM ( ) y ALU ( $\nabla$ ). Cada punto representa el valor promedio de tres repeticiones y el error estándar. Letras diferentes indican diferencias significativas $(\alpha=0.05$, prueba Tukey).

La fuente de carbono tiene un claro efecto sobre la AE del BS producido $(p<0.05)$, la mejor AE

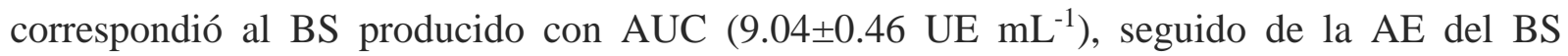


producido con AH (5.48 \pm 0.11$)$, enseguida la AE del BS producido con ALU (3.74 \pm 0.10$)$ y por último la AE del BS producido con PCM (1.66士0.45). La AE del BS producido a partir de HXD

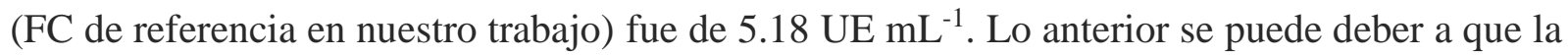
FC determinó la estructura molecular del BS producido, que a su vez modificó su AE. Se ha propuesto que el incremento de la solubilización de hidrocarburos por el biosurfactante Alasan de $A$. radioresistens KA 53 depende de la naturaleza hidrofóbica de las moléculas de Alasan y no de su capacidad para formar micelas (Barkay y col. 1999).

\subsection{Selección de la mejor fuente de carbono para la producción del biosurfactante de A. bouvetii}

Los resultados obtenidos en el punto anterior (7.1) fueron determinados en una escala de producción pequeña $(50 \mathrm{~mL})$ y difícilmente escalable. Por lo tanto, fue necesario darle validez a los resultados de este estudio. La decisión que se tomó fue seleccionar la mejor fuente de carbono hidrofóbica para producir el BS de A. bouvetii en un biorreactor airlift de $1 \mathrm{~L}$. La selección de la FC se realizó mediante una matriz de decisión (Tabla 2) que consideró diferentes

criterios de viabilidad, previamente explicados en el punto 6.6.2. Cabe mencionar que una matriz de decisión es un instrumento que permite identificar y analizar la fuerza de las relaciones entre diversos conjuntos de información para facilitar la toma de decisiones. En la matriz de decisión se observa que el AUC fue la FC hidrofóbica con la mejor calificación (0.77) y por lo tanto se seleccionó como la materia prima con la más alta factibilidad técnica y económica para la producción del BS de $A$. bouvetii en un biorreactor airlift. 


\section{de diferentes fuentes de carbono hidrofóbicas}

Tabla 2. Matriz de decisión para elegir la mejor fuente de carbono para la producción del BS.

\begin{tabular}{|c|c|c|c|c|c|c|c|c|c|c|c|c|}
\hline \multirow{2}{*}{\multicolumn{2}{|c|}{ Criterio }} & \multirow{2}{*}{ 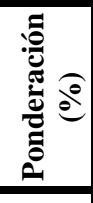 } & \multirow{2}{*}{ Subcriterios } & \multirow{2}{*}{ 巳 } & \multicolumn{8}{|c|}{ FUENTE DE CARBONO } \\
\hline & & & & & \multicolumn{2}{|c|}{ AH } & \multicolumn{2}{|c|}{ AUC } & \multicolumn{2}{|c|}{ PCM } & \multicolumn{2}{|c|}{ ALU } \\
\hline \multirow{12}{*}{ 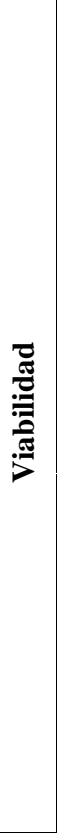 } & \multirow{3}{*}{ 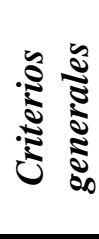 } & \multirow{3}{*}{ 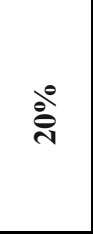 } & $\begin{array}{l}\text { a) Competencia con otros } \\
\text { proyectos }\end{array}$ & $5 \%$ & iii & 0 & $\mathrm{i}$ & 0.05 & iii & 0 & ii & 0.025 \\
\hline & & & $\begin{array}{l}\text { b) Se cuenta con la } \\
\text { información suficiente }\end{array}$ & $7 \%$ & i & 0.07 & ii & 0.035 & $\mathrm{i}$ & 0.07 & ii & 0.035 \\
\hline & & & $\begin{array}{l}\text { c) Beneficios adicionales de } \\
\text { utilizar la fuente de carbono }\end{array}$ & $8 \%$ & ii & 0.04 & $\mathrm{i}$ & 0.08 & ii & 0.04 & $\mathrm{i}$ & 0.08 \\
\hline & \multirow{4}{*}{ 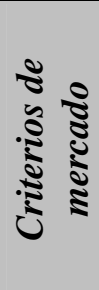 } & \multirow{4}{*}{ है } & $\begin{array}{l}\text { a) Existencia de incentivos } \\
\text { fiscales }\end{array}$ & $5 \%$ & iii & 0 & ii & 0.025 & iii & 0 & $\mathrm{i}$ & 0.05 \\
\hline & & & $\begin{array}{l}\text { b) Disponibilidad de la fuente } \\
\text { de carbono }\end{array}$ & $10 \%$ & $\mathbf{i}$ & 0.1 & ii & 0.05 & $\mathrm{i}$ & 0.1 & ii & 0.05 \\
\hline & & & $\begin{array}{l}\text { c) Precio de la fuente de } \\
\text { carbono }\end{array}$ & $14 \%$ & iii & 0 & $\mathrm{i}$ & 0.14 & ii & 0.07 & $\mathrm{i}$ & 0.14 \\
\hline & & & d) Pretratamiento & $6 \%$ & i & 0.06 & ii & 0.03 & ii & 0.03 & iii & 0 \\
\hline & \multirow{5}{*}{ 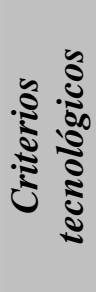 } & \multirow{5}{*}{$\begin{array}{l}89 \\
10\end{array}$} & a) Infraestructura tecnológica & $5 \%$ & i & 0.05 & $\mathrm{i}$ & 0.05 & $\mathrm{i}$ & 0.05 & $\mathrm{i}$ & 0.05 \\
\hline & & & b) $\mu_{\max }$ & $9 \%$ & $\mathbf{i}$ & 0.09 & ii & 0.045 & ii & 0.045 & ii & 0.045 \\
\hline & & & c) $\lambda$ & $9 \%$ & ii & 0.045 & ii & 0.045 & iii & 0 & iii & 0 \\
\hline & & & d) $X_{\max }$ & $7 \%$ & $\mathbf{i}$ & 0.07 & $\mathrm{i}$ & 0.07 & ii & 0.035 & ii & 0.035 \\
\hline & & & e) $\mathbf{A E}$ & $15 \%$ & ii & 0.075 & $\mathrm{i}$ & 0.15 & iii & 0 & iii & 0 \\
\hline \multicolumn{2}{|r|}{ Total } & $100 \%$ & & $100 \%$ & & 0.60 & & 0.77 & & 0.44 & & 0.51 \\
\hline
\end{tabular}

\subsubsection{Caracterización cualitativa del aceite usado de cocina}

Hasta esta etapa del estudio, la FC con la mayor factibilidad técnica y económica fue el AUC pero se desconocía su composición. Por lo tanto, se juzgó pertinente realizar una caracterización cualitativa del AUC utilizado en este estudio como FC para A. bouvetii. El porcentaje de acidez del AUC fue de 0.65. El cromatograma de ión total y el porcentaje de ácidos grasos presentes en el AUC se presentan en la Figura 9.

En el cromatograma de ión total se observan los tiempos de retención de los ésteres metílicos de ácidos grasos sintetizados a partir del AUC. Los esteres metílicos identificados fueron aquellos derivados del: (i) ácido hexadecanoico o palmítico (9.423 min); (ii) ácido 9,12- 
octadecadienoico o linoleico (11.507 min); (iii) ácido 9-octadecenoico u oleico (11.574 min) y (iv) ácido octadecanoico o esteárico (11.875 min).
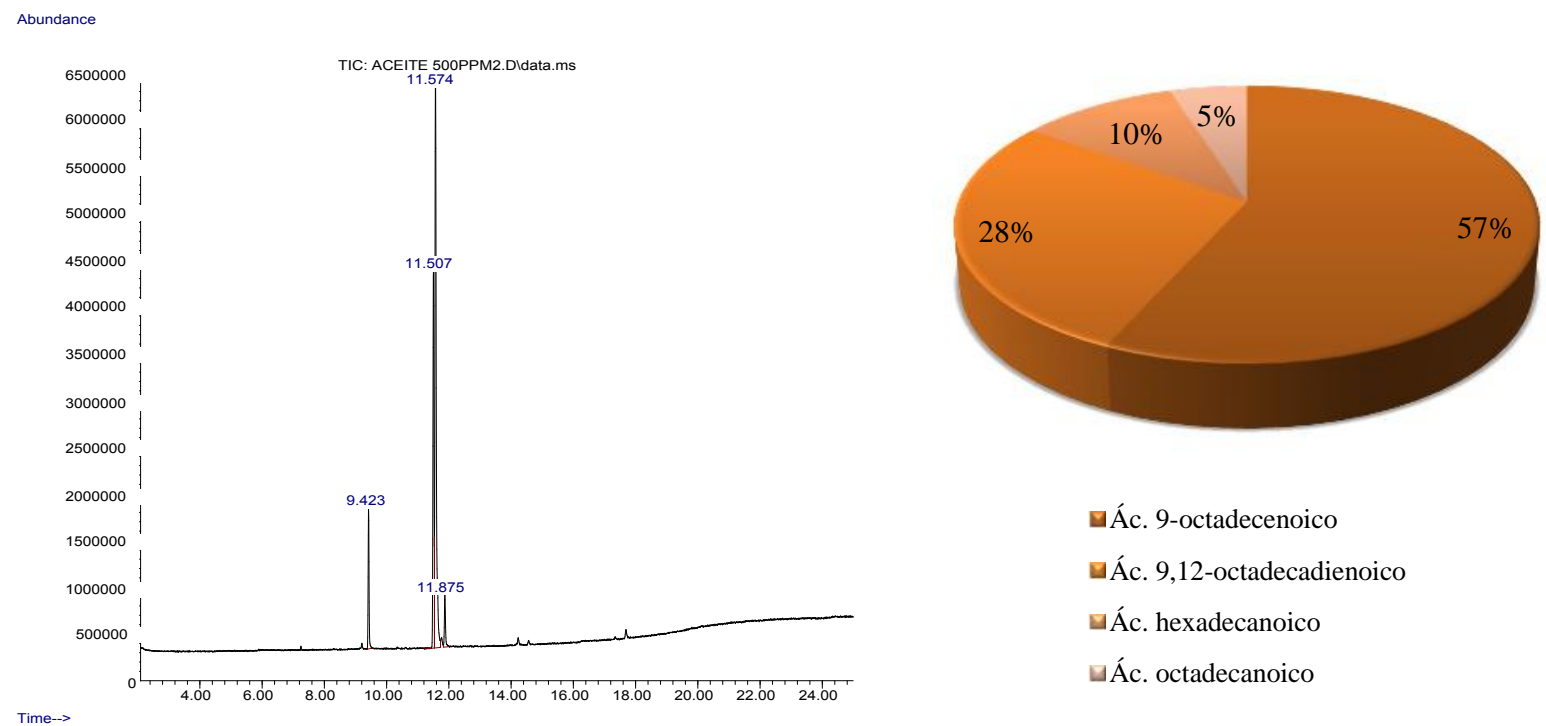

Figura 9. Cromatograma de ión total (izq.) y composición de ácidos grasos presentes en el AUC (der.)

La composición de ácidos grasos y una mayor presencia de ácido Oleico (57 \%) son características del aceite de girasol (Brevedan y col., 2000). Esta caracterización puede ser empleada como una medida de la calidad del AUC al utilizarlo como materia prima para la producción a gran escala del BS de $A$. bouvetii. Además, el método propuesto para caracterizar el AUC (ver sección 6.3) se puede utilizar como una técnica para evaluar los posibles proveedores del aceite.

\subsection{Producción del BS de $A$. bouvetii en un biorreactor airlift}

Una vez caracterizado cualitativamente el AUC, los parámetros técnicos de crecimiento determinados anteriormente se validaron con cinéticas de producción del BS en biorreactor airlift (BAL) utilizando AUC como única fuente de carbono y energía. Un BAL es un reactor agitado neumáticamente por medio del suministro de una fase gaseosa en la parte inferior. La 
principal ventaja del BAL en comparación con biorreactores convencionales (tanque agitado) son la eficiencia de mezclado y mayores tasas de aireación con un menor consumo de energía (Chisti, 1989). La hidrodinámica de BAL trifásicos se ha estudiado antes en nuestro laboratorio; por ejemplo, se optimizó la operación de la aireación con estrategias de velocidad superficial de la fase gaseosa variable (Lizardi-Jiménez y col., 2012). La velocidad de la fase gaseosa (Ug) es un factor que modifica la hidrodinámica en los BAL y ésta a su vez podría modificar los parámetros cinéticos de crecimiento previamente determinados en botellas serológicas. Para determinar si es que había variaciones en los parámetros técnicos debidas a cambios en los fenómenos de transporte de masa, se evaluó la producción del BS en dos corridas independientes a dos Ug constantes ( 0.6 y $2.7 \mathrm{~cm} \mathrm{~s}^{-1}$ ) para determinar la magnitud de estas modificaciones.

\subsubsection{Cinética de crecimiento de $A$. bouvetii en un biorreactor Airlift}

En la Figura 10 se presenta el crecimiento de $A$. bouvetii en un BAL a dos Ug $\left(0.6\right.$ y $\left.2.7 \mathrm{~cm} \mathrm{~s}^{-1}\right)$ y en botellas serológicas. Todos los ensayos se prolongaron por $72 \mathrm{~h}$ de cultivo.

El crecimiento de $A$. bouvetii se observó similar en los ensayos realizados, con la misma tendencia, de hecho no hubo diferencias significaticas $(p<0.05)$ en el crecimiento máximo $\left(\mathrm{X}_{\max }\right)$ de la bacteria en el BAL operado a Ug alta y en botellas serológicas $\left(1.45 \pm 0.15 \times 10^{9} \mathrm{y}\right.$ $1.82 \pm 0.07 \times 10^{9} \mathrm{UFC}^{-1}$, respectivamente). El menor $\mathrm{X}_{\max }$ se observó en el BAL operado a Ug baja con una concentración de $0.14 \pm 0.07 \times 10^{9} \mathrm{UFC}^{-1}$. El crecimiento similar en BAL y en botellas serológicas se explica por el mecanismo de consumo directo de la FC hidrofóbica, en otras palabras que las resistencias a los fenómenos de transporte del aceite de la fase orgánica a la acuosa son irrelevantes debido a que la células de $A$. bouvetii se adhieren a las gotas hidrofóbicas de la FC. En este sentido, hay reportes que mencionan diferentes estrategias de 
adhesión a gotas de compuestos hidrofóbicos; por ejemplo, la cepa A. venetianus VE-C3 interactúa con gotas de Diesel por un proceso complejo: la presencia de alcanos inducen la glicosilación de las proteínas de membrana que participan en la absorción de aceite (Baldi y col., 2003) y se forma un biopelícula favorecida por la producción de exopolisacáridos. La agregación célula a célula es paralela a un aumento en la hidrofobicidad celular y seguida de una internalización de las gotas del Diesel (Baldi y col., 1999). El cambio en la hidrofobicidad celular paralelo a un consumo de HXD por A. bouvetii ya fue reportado (Tzintzun-Camacho y col., 2012).

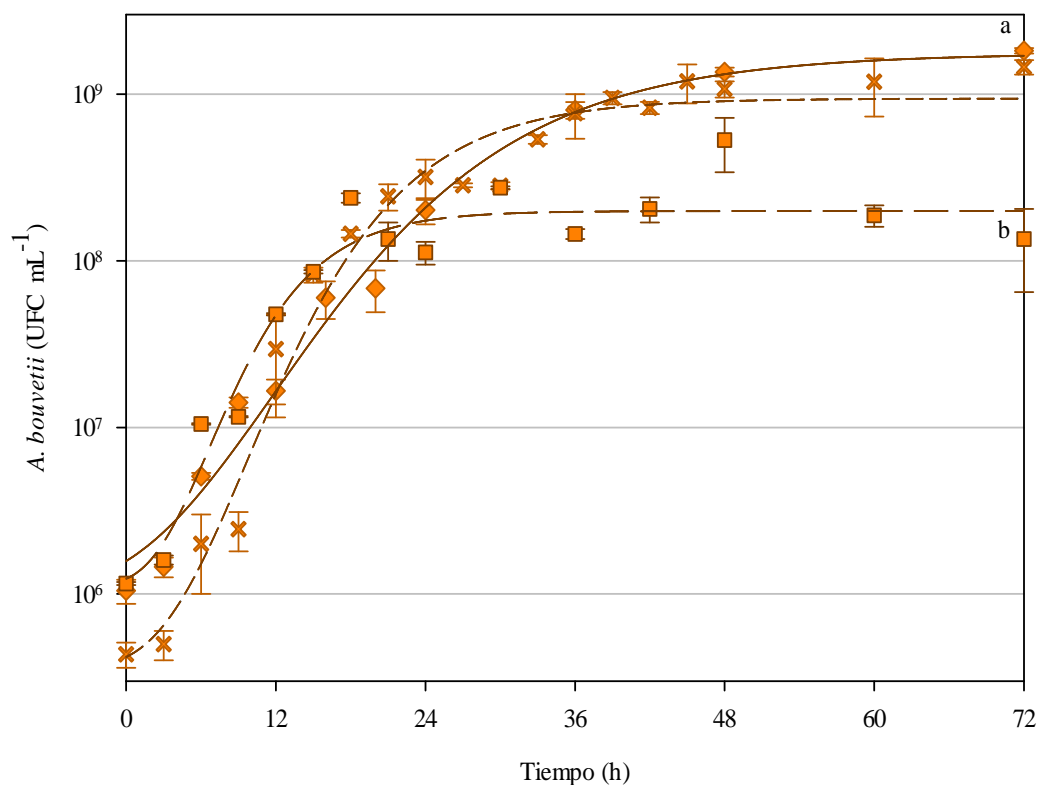

Figura 10. Cinéticas de crecimiento de $A$. bouvetii ajustadas con el modelo de Gompertz. Crecimiento: en botella serológica ( ) y curva (línea continua), en BAL a Ug alta ( $X$ ) y curva ( ), en BAL a Ug baja ( ) y curva ( -). Cada punto representa el valor promedio de tres repeticiones y el ES. Letras diferentes indican diferencias significativas $(\alpha=0.05$, prueba Tukey).

Con estos resultados, el modelo reparametrizado de Gompertz (ver ecuación 6.3) se ajustó a los datos experimentales de crecimiento mostrados en la Figura 10 y se compararon los parámetros cinéticos estimados. Las curvas de crecimiento ajustadas representaron al menos el $97 \%$ de la variación de los datos experimentales $\left(\mathrm{R}^{2} \geq 0.97\right)$. 


\subsubsection{Parámetros cinéticos de crecimiento de $A$. bouvetii en un bioreactor airlift.}

En la Tabla 3 se listan los parámetros cinéticos de crecimiento ( $\mu_{\max }, \lambda$ y D) estimados con el modelo de Gompertz en BAL (operado, en corridas independientes, a dos Ug) y en botellas serológicas. La tasa específica de crecimiento $\left(\mu_{\max }\right)$ estimada en el BAL operado a cualquier Ug fue significativamente mayor $(p<0.05)$ a la $\mu_{\max }$ estimada en botellas serológicas $(1.7$ veces $)$. En la duración de la fase lag $(\lambda)$ no hubo diferencias significativas en ningún biorreactor ensayado. Los mayores cambios en la densidad poblacional (D) de A. bouvetii se observaron en el BAL operado a Ug alta y en botellas serológicas.

Tabla 3. Parámetros cinéticos de crecimiento estimados con el modelo de Gompertz en distintos biorreactores. Letras diferentes indican diferencias significativas $(\alpha=0.05$, prueba Tukey).

\begin{tabular}{c|cc|cc|cc|c}
\hline \multirow{2}{*}{ Biorreactor } & \multicolumn{2}{|c|}{$\boldsymbol{\mu}_{\max }$} & \multicolumn{2}{|c|}{$\lambda$} & \multicolumn{2}{|c|}{ D } & $\mathbf{X}_{\max }$ \\
\cline { 2 - 8 } & $\mathrm{h}^{-1}$ & $\mathrm{ES}$ & $\mathrm{h}$ & $\mathrm{ES}$ & & $\mathrm{ES}$ & $\mathrm{UFC} \mathrm{mL}^{-1}$ \\
\hline Botella serológica & $0.24^{\mathrm{b}}$ & 0.02 & 0.71 & 0.83 & $7.42^{\mathrm{a}}$ & 0.19 & $1.82 \times 10^{9 \mathrm{a}}$ \\
BAL $\left(\mathrm{Ug} 2.7 \mathrm{~cm} \mathrm{~s}^{-1}\right)$ & $0.42^{\mathrm{a}}$ & 0.03 & 2.67 & 0.79 & $7.85^{\mathrm{a}}$ & 0.13 & $1.45 \times 10^{9 \mathrm{a}}$ \\
BAL $\left(\mathrm{Ug} 0.6 \mathrm{~cm} \mathrm{~s}^{-1}\right)$ & $0.40^{\mathrm{a}}$ & 0.06 & 1.93 & 0.98 & $5.17^{\mathrm{b}}$ & 0.13 & $0.14 \times 10^{9 \mathrm{~b}}$ \\
\hline
\end{tabular}

*ES es el error estándar de la estimación.

Los anteriores resultados demostraron que el crecimiento de A. bouvetii en el BAL se favoreció en rapidez, especialmente después de la fase lag, pero no en magnitud. La hidrodinámica en el BAL permitió una mejor mezcla de nutrientes y células beneficiando el incremento en la $\mu_{\max }$ de A. bouvetii. El $\mathrm{X}_{\max }$ en el BAL operado a Ug alta se alcanzó en 24 h y en botellas serológicas se observó el mismo $\mathrm{X}_{\max }$ en $48 \mathrm{~h}$. El aumento en $\mu_{\max }$ también podría incrementar la tasa de producción del BS debido a que la producción estuvo parcialmente ligada al crecimiento de $A$. bouvetii. Por lo tanto, se determinó la actividad emulsificante del BS producido en el BAL y se ajustó el modelo de producción exponencial máximo (ver ecuación 6.4) para comparar los parámetros técnicos de producción del BS en los dos sistemas de cultivo. 


\subsubsection{Actividad emulsificante del biosurfactante de $A$. bouvetii producido en BAL}

En la Figura 11 se muestra la actividad emusificante (AE) del BS a lo largo de $72 \mathrm{~h}$ de cultivo en: (i) BAL operado con una Ug de $2.7 \mathrm{~cm} \mathrm{~s}^{-1}$, (ii) BAL oprerado con una $U g$ de $0.6 \mathrm{~cm} \mathrm{~s}^{-1} \mathrm{y}$ (iii) botellas serológicas.

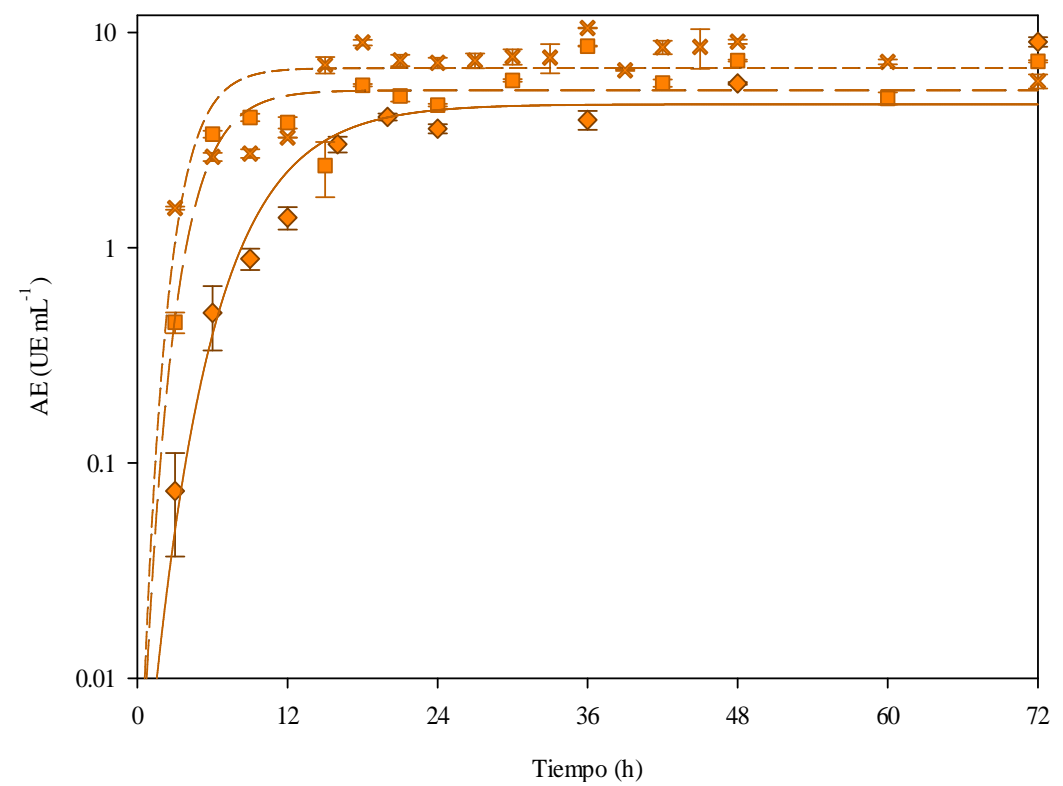

Figura 11. Cinética de AE ajustadas al modelo de producción. AE: en botella serológica ( ) y curva (línea continua), en BAL a Ug alta $(X)$ y curva ( ), en BAL a Ug baja ( ) y curva (-). Cada punto representa el valor promedio de tres repeticiones y el error estándar.

La $\mathrm{AE}$ máxima $\left(\mathrm{AE}_{\max }\right)$ del $\mathrm{BS}$ producido en los biorreactores ensayados no fue significativamente diferente $(p<0.05)$. En el $\mathrm{BAL}$, las $\mathrm{AE}_{\max }$ se determinaron a las $36 \mathrm{~h}$ de cultivo con $\mathrm{Ug}$ alta fue de $10.49 \pm 0.04$ y con Ug baja fue de $8.64 \pm 0.04 \mathrm{UE} \mathrm{mL}^{-1}$, la $\mathrm{AE}_{\max }$ en botellas serológicas se determinó a las $72 \mathrm{~h}$ de cultivo $\left(9.04 \mathrm{UE} \mathrm{mL}^{-1}\right)$. Análogos a los resultados de crecimiento de A. bouvetii observados en los diferentes biorreactores, la $\mathrm{AE}_{\max }$ se alcanzó en menor tiempo en los BAL. Para dar mayor solidez a la anterior observación, el modelo de producción exponencial máximo (ver ecuación 6.4) se ajustó a los datos experimentales de AE, 
como se muestra en la Figura 11. El modelo representó al menos el 98\% de la variación de los datos de $\mathrm{AE}\left(\mathrm{R}^{2} \searrow 0.98\right)$.

Los parámetros técnicos estimados con el modelo de producción exponencial máximo se presentan en la Tabla 4. En este estudio, el parámetro $v$ se definió como la tasa máxima de AE en $\mathrm{h}^{-1}$ y el parámetro $\mathrm{P}_{\max }$ como el cambio máximo de expresión de la AE durante la producción del BS. Las $v$ estimadas en el BAL fueron significativamente mayores $(p<0.05)$ a la $v$ estimada en las botellas serológicas (2 veces). $\mathrm{P}_{\max }$ no resultó significativamente diferente en ninguno de los sistemas ensayados, es decir que la AE cambió al menos 8 UE durante las cinéticas de producción. Los resultados anteriores dieron mayor validez a los resultados ya observados con la $\mathrm{AE}_{\max } \mathrm{y}$ el crecimiento de $A$. bouvetii. La producción de BS en un BAL disminuyó el tiempo de cultivo debido a una mayor velocidad de crecimeinto de la cepa, lo anterior se explicó asumiendo que la síntesis del BS estuvo ligado o parcialmente ligado al crecimiento del microorganismo.

Tabla 4. Parámetros de AE estimados con el modelo de producción exponencial máximo en diferentes biorreactores. Letras diferentes indican diferencias significativas $(\alpha=0.05$, prueba Tukey).

\begin{tabular}{c|cc|cc|c}
\hline \multirow{2}{*}{ Biorreactor } & \multicolumn{2}{|c|}{$\boldsymbol{v}$} & \multicolumn{2}{|c|}{$\mathbf{P}_{\max }$} & $\mathbf{A E}_{\max }$ \\
& $\mathrm{h}^{-1}$ & $\mathrm{ES}$ & & $\mathrm{ES}$ & $\mathrm{UE} \mathrm{mL}^{-1}$ \\
\hline Botellas serológicas & $0.21^{\mathrm{b}}$ & 0.01 & $8.44^{\mathrm{b}}$ & 0.11 & $9.04^{\mathrm{a}}$ \\
BAL $\left(\mathrm{Ug} 2.7 \mathrm{~cm} \mathrm{~s}^{-1}\right)$ & $0.52^{\mathrm{a}}$ & 0.04 & $8.83^{\mathrm{a}}$ & 0.06 & $10.49^{\mathrm{a}}$ \\
BAL $\left(\mathrm{Ug} 0.6 \mathrm{~cm} \mathrm{~s}^{-1}\right)$ & $0.42^{\mathrm{a}}$ & 0.03 & $8.59^{\mathrm{b}}$ & 0.07 & $8.64^{\mathrm{a}}$ \\
\hline
\end{tabular}

*ES es el error estándar de la estimación.

Los resultados obtenidos en el BAL demostraron que los parámetros cinéticos de crecimiento $\mathrm{X}_{\max }, \lambda, \mathrm{D}$ de $A$. bouvetii y las $\mathrm{AE}_{\max }$ del BS producido a partir de AUC no fueron diferentes a los obtenidos en botellas serológicas. El único cambio significativo se observó en la rapidez de crecimiento de la cepa $\left(\mu_{\max }\right)$ que a su vez modificó la tasa de cambio de la expresión de AE (v), 
siendo aproximadamente del doble de magnitud en el BAL con respecto a las botellas serológicas. Por lo tanto, los parámetros técnicos estimados a partir de datos experimentales en botellas serológicas $\left(\mathrm{X}_{\max }, \lambda, \mathrm{D}\right.$ y $\left.\mathrm{AE}_{\max }\right)$ se validaron o bien se ajustaron $\left(\mu_{\max } \mathrm{y} v\right)$ para la producción del BS de A. bouvetii.

Además de la validación de parámetros técnicos, en nuestro grupo de trabajo se manifestó un gran interes en estimar el costo de producción del BS de A. bouvetii ya que es el principal factor que limita el uso de BS en la industria (Syldatk y Hausman, 2010).

\subsection{Análisis de costos de producción del BS de A. bouvetii a partir de diferentes fuentes de carbono}

El costo de producción de biosurfactantes se eleva por el uso de fuentes de carbono caras, concentraciones de producto limitadas, bajos rendimientos y la formación de mezclas complejas en lugar de los compuestos puros (Mukherjee y col., 2006; Makkar y col., 2011). Por lo tanto, el estimar el costo de producción del BS de A. bouvetii se consideró necesario para determinar su factibilidad económica. Los costos de producción se estimaron tomando en cuenta tres variables: el precio de la fuente de carbono $\left(\mathrm{S}_{\mathrm{FC}}\right)$, concentración final del BS $\left(\mathrm{C}_{\mathrm{BS}}\right)$ y fracción de costo de purificación con respecto al costo total de producción $\left(\mathrm{S}_{\mathrm{P}}\right)$.

La ecuación 6.15 se desarrolló especialmente para la calcular el costo del BS en función de las variables antes mencionadas (ver sección 6.6.4).

$$
S_{B S}=\frac{0.0353+C_{F C} S_{F C}}{0.3 C_{B S}\left(1-S_{P}\right)}
$$


Donde $\mathrm{S}_{\mathrm{BS}}$ se expresó en unidades de dólares estadounidenses (USD) por kg de BS, $\mathrm{C}_{\mathrm{BS}}$ se expresó en kg de BS por L de medio de cultivo, $\mathrm{S}_{\mathrm{FC}}$ se expresó en USD por kg de la FC, $\mathrm{S}$ tomó valores de 0 a 0.6 y $\mathrm{C}_{\mathrm{FC}}$ es la concentración inicial de $\mathrm{FC}$ en $\mathrm{kg} \mathrm{L}^{-1}$ de $\mathrm{MM}$.

Se realizó una revisión de la literatura (1979-2012) para determinar un rango para $\mathrm{C}_{\mathrm{BS}}$. Se encontró que las especies del género Acinetobacter producen $\mathrm{BS}$ con valores para $\mathrm{C}_{\mathrm{BS}}$ que fluctúan entre 0.041 y $3.78 \mathrm{~g} \mathrm{~L}^{-1}$ de cultivo (Rosenberg y col., 1979; Chamanrokh y col., 2008). El costo de producción del BS se estimó en función de: (i) $\mathrm{C}_{\mathrm{BS}}$ y $\mathrm{S}_{\mathrm{FC}}$ (Figura 12a), (ii) $\mathrm{C}_{\mathrm{BS}}$ y $\mathrm{S}_{\mathrm{P}}$ (Figura 12b); se utilizó $\mathrm{C}_{\mathrm{FC}}$ igual a $11.1 \mathrm{~g} \mathrm{~L}^{-1}$ y $\mathrm{S}_{\mathrm{FC}}$ igual a $9.13 \mathrm{USD} \mathrm{kg}^{-1}$ cuando fue necesario. En la Figura 12a, se observa que a $\mathrm{S}_{\mathrm{FC}}$ bajos (menores de $1 \mathrm{USD} \mathrm{kg}^{-1}$ ) y $\mathrm{C}_{\mathrm{BS}}$ superiores a $1.16 \mathrm{~g}$ $\mathrm{L}^{-1}$ el $\mathrm{S}_{\mathrm{BS}}$ fue de $300 \mathrm{USD} \mathrm{kg}^{-1}$; cuando $\mathrm{S}_{\mathrm{FC}}$ fue igual a $8.19 \mathrm{USD} \mathrm{kg}^{-1}$, la $\mathrm{C}_{\mathrm{BS}}$ tuvo que ser superior a $3.41 \mathrm{~kg} \mathrm{~L}^{-1}$ para que el $\mathrm{S}_{\mathrm{BS}}$ fuera el mismo. En la Figura 12b, se observa que sólo con $\mathrm{C}_{\mathrm{BS}}$ superiores a $1.91 \mathrm{~kg} \mathrm{~L}^{-1}$ y $\mathrm{S}_{\mathrm{P}}$ menores a $0.3 \mathrm{el} \mathrm{S}_{\mathrm{BS}}$ fue de $314 \mathrm{USD} \mathrm{kg}^{-1}$.
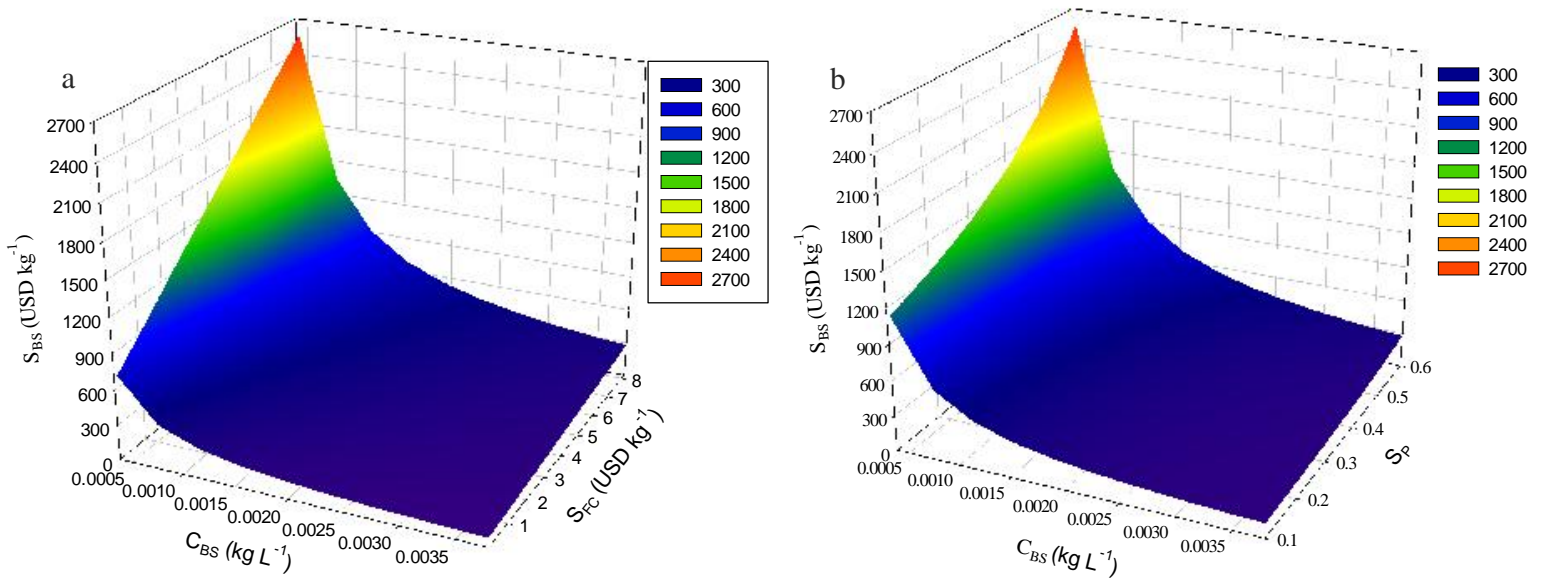

Figura 12. Estimación del costo (USD) de producción del BS de A. bouvetii (SBS) en función de: (a) la concentración final de $\mathrm{BS}\left(\mathrm{C}_{\mathrm{BS}}\right)$ y precio de la $\mathrm{FC}\left(\mathrm{S}_{\mathrm{FC}}\right)$, (b) la $\mathrm{C}_{\mathrm{BS}}$ y del porcentaje del costo de purificación con respecto al costo total de producción de BS (SP).

Un $\mathrm{S}_{\mathrm{BS}}$ menor a $300 \mathrm{USD} \mathrm{kg}^{-1}$ resultó de interés debido a que el costo de producción de Emulsan fue de 270 USD kg-1, $50 \%$ del precio comercial del Emulsan que se cotizó en $540 \mathrm{USD} \mathrm{kg}^{-1}$ 
(Dunao Co., China, 2013). De hecho, para que el BS de A. bouvetii pudiera competir con el Emulsan se tendría que: (i) utilizar una FC con un precio menor a $8.19 \mathrm{USD} \mathrm{kg}^{-1}$, (ii) producir en una $\mathrm{C}_{\mathrm{BS}}$ mayor a $2.23 \mathrm{~g} \mathrm{~L}^{-1}$ y (iii) los costos de purificación no asciendan a más del $30 \%$ del costo total de producción. Otro BS ampliamente utilizado, especialmente en la industria de los alimentos, es la lecitina de soya con un precio comercial que varía entre 30 y $40 \mathrm{USD} \mathrm{kg}^{-1}$ (Xi'an Realin Biotechnology Co.). Para que el BS de A. bouvetii lograra competir con el costo de producción de la lecitina (20 USD kg-1) sería necesario que: (i) la cepa produjera al menos 7.56 $\mathrm{g} \mathrm{L}^{-1}$, (ii) el costo de la FC a lo más fuera de $0.03 \mathrm{USD} \mathrm{kg}^{-1}$ y (iii) los costos de purificación no ascendieran a más del 30\% del costo total de producción.

A partir de las anteriores consideraciones, fue lógico determinar cuáles FC eran las adecuadas para la producción del BS. Cabe recordar que el precio de venta de las FC se cotizó directamente con los proveedores, los valores, expresados en USD kg-1, fueron los siguientes: AH en 8.19, el AUC en 0.03 , el PCM en 0.88 y el ALU en 0.65. En el presente trabajo se determinó experimentalmente sólo la AE del BS pero no se determinó la concentración $\mathrm{C}_{\mathrm{BS}}$. En el 2012 Chen y col. optimizaron la producción del BS producido por Acinetobacter sp. YC-X 2 utilizando HXD como FC ( $\mathrm{C}_{\mathrm{BS}}$ igual a $\left.1.15 \mathrm{~g} \mathrm{~L}^{-1}\right)$, se relacionó la $\mathrm{C}_{\mathrm{BS}}$ optimizada con la AE del BS de A. bouvetii producido a partir de $\operatorname{HXD}\left(5.18 \mathrm{UE} \mathrm{mL}^{-1}\right.$ ) y se determinó que un mg de BS de Acinetobacter emulsificó 4.5 Unidades. Por lo tanto, las $\mathrm{C}_{\mathrm{BS}}$ estimadas para cada $\mathrm{FC}$ en $\mathrm{kg}$ $\mathrm{L}^{-1}$ fueron las siguientes: con AH de 1.22, con AUC de 2.01, con ALU de 0.83 y con PCM 0.37. El costo de producción $\left(\mathrm{S}_{\mathrm{BS}}\right)$ del BS producido a partir de distintas FC hidrofóbicas (Figura 13) se estimó con la ecuación $6.15, \mathrm{~S}_{\mathrm{P}}$ de $0.6, \mathrm{C}_{\mathrm{FC}}$ de $11.1 \mathrm{~g} \mathrm{~L}^{-1}$ para las renovables y $\mathrm{C}_{\mathrm{FC}}$ de $13 \mathrm{~g} \mathrm{~L}$ ${ }^{1}$ para las no renovables. EL BS producido a partir de PCM fue el de mayor costo de producción 
(1058 USD kg-1) debido a la baja $C_{B S}$ que se alcanzó, ya que $S_{B S}$ es bajo sólo es necesario optimizar $\mathrm{C}_{\mathrm{BS}} 3.5$ veces para que se pudiera competir con el Emulsan en cuanto a costos de producción. Los $\mathrm{S}_{\mathrm{BS}}$ utilizando ALU como FC ascendieron a $439 \mathrm{USD} \mathrm{kg}^{-1}$, optimizar 1.5 veces la $C_{B S}$ de este estudio reduciría los $S_{B S}$ a 293 USD kg$^{-1}$. Los $S_{B S}$ utilizando AH como FC fueron de $864 \mathrm{USD} \mathrm{kg}^{-1}$, duplicar $\mathrm{C}_{\mathrm{BS}}$ y reducir $\mathrm{S}_{\mathrm{P}}$ a $0.4 \mathrm{~S}_{\mathrm{BS}}$ disminuiría a $288 \mathrm{USD} \mathrm{kg}^{-1}$.

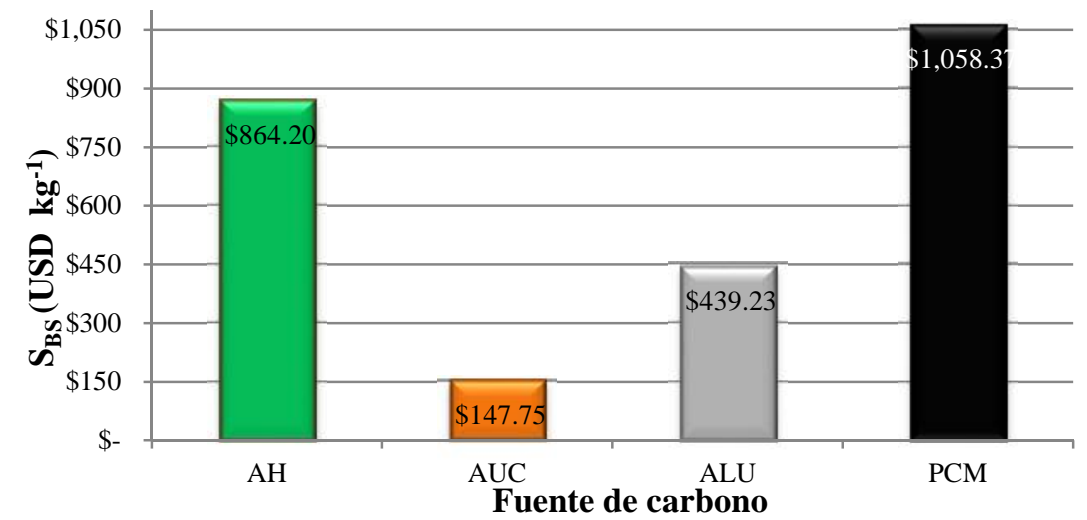

Figura 13. Costo de producción del BS de A. bouvetii $\left(\mathrm{S}_{\mathrm{BS}}\right)$ a partir de distintas fuentes de carbono.

El BS producido a partir de AUC fue el de menor costo de producción (148 USD kg ${ }^{-1}$ ) por su bajo $\mathrm{S}_{\mathrm{FC}}$ y la alta $\mathrm{C}_{\mathrm{BS}}$ que se estimó, el costo de producción fue menor al del Emulsan y con duplicar $\mathrm{C}_{\mathrm{BS}}$ y reducir $\mathrm{S}_{\mathrm{P}}$ a $0.3 \mathrm{~S}_{\mathrm{BS}}$ posiblemente se podría competir con la lecitina de soya.

Por lo anterior, con el modelo propuesto para la estimación de los costos de producción del BS fue posible: (i) determinar las condiciones necesarias $\left(\mathrm{C}_{\mathrm{BS}}, \mathrm{S}_{\mathrm{FC}}, \mathrm{y} \mathrm{S}_{\mathrm{P}}\right)$ para alcanzar un costo de producción específico, (ii) estimar los costos de producción del BS de A.bouvetii a partir de distintas FC hidrofóbicas y (iii) determinar las condiciones óptimas para reducir los costos de producción del BS con las diferentes FC. 


\section{Conclusiones}

A. bouvetii asimiló aceite de higuerilla, aceite usado de cocina, aceite lubricante usado y petróleo crudo Maya como únicas fuentes de carbono y energía. A. bouvetii no fue capaz de asimilar las dos fuentes de carbono hidrofílicas ensayadas: D-glucosa y D-fructosa.

A. bouvetii produjo BS con las cuatro fuentes de carbono hidrofóbicas ensayadas. En todos los casos, la producción del BS estuvo parcialmente ligada al crecimiento de A. bouvetii.

Se estimaron los parámetros técnicos del crecimiento de A. bouvetii y de producción del biosurfactante a partir de cuatro fuentes de carbono hidrofóbicas. Los mejores parámetros técnicos de crecimiento $\left(\mu_{\max }, \lambda, \mathrm{D}\right.$ y $\left.\mathrm{X}_{\max }\right)$ se observaron al utilizar aceite de higuerilla $\left(0.26 \mathrm{~h}^{-}\right.$ 1, $2.95 \mathrm{~h}, 7.09$ y $1.71 \times 10^{9} \mathrm{UFC}_{\mathrm{mL}}^{-1}$, respectivamente) y aceite usado de cocina $\left(0.24 \mathrm{~h}^{-1}, 0.71\right.$ h, 7.43 y $1.82 \times 10^{9} \mathrm{UFC}_{\mathrm{mL}^{-1}}$ respectivamente) como únicas fuentes de carbono y energía. La mayor actividad emulsificante del BS de A. bouvetii (9.04 $\mathrm{UE} \mathrm{mL}^{-1}$ ) se observó al utilizar aceite usado de cocina como única fuente de carbono y energía a las 72 h de cultivo.

La mejor fuente de carbono hidrofóbica para la producción del biosurfactante de A. bouvetii fue el aceite usado de cocina con base en un análisis de criterios de viabilidad.

La factibilidad técnica de la producción del biosurfactante de A. bouvetii fue demostrada al no encontrar diferencias entre los parámetros técnicos $\lambda, \mathrm{D}, \mathrm{X}_{\max } \mathrm{y} \mathrm{AE}_{\max }$ estimados a partir de datos experimentales determinados en botellas serológicas y en biorreactor airlift a partir de aceite usado de cocina como fuente de carbono. Además, los parámetros técnicos $\mu_{\max } \mathrm{y} v$ fueron 1.7 veces mayores en un biorreactor airlift. 
Evaluación de la eficiencia de producción del biosurfactante de Acinetobacter bouvetii a partir de diferentes fuentes de carbono hidrofóbicas

La factibilidad económica de la producción del biosurfactante de A. bouvetii fue validada. El costo de producción del BS de A. bouvetii a partir de aceite usado de cocina fue competitivo con el costo de producción del biosurfactente comercial Emulsan. 


\section{Bibliografía}

Abdel-El-Haleem D. (2003). Acinetobacter: environmental and biotechnological applications. African Journal of Biotechnology, 2: 71-94.

Amaral P. F. F., Coelho M. A. Z., Marrucho I. M. J., Coutinho J. A. P. (2010). Biosurfactants from Yeasts: Characteristics, Production and Application. Advances in Experimental Medicine and Biology. Editorial Ramkrishna Sen. Primera Edición. 672: 236-149.

Amoabediny G., Rezvani M., Rashedi H., Jokari S., Chamanrokh P., Mazaheri M., Ghavami M., Yazdian F. (2010). Application of a novel method for optimization of bioemulsan production in a miniaturized bioreactor. Bioresorce Technology, 101: 9758-9764.

Baldi F., Ivosevic N., Minacci A., Pepi M., Fani R., Svetlicic V., Zutic V. (1999). Adhesion of Acinetobacter venetianus to diesel fuel droplets studied with in situ electrochemical and molecular probes. Applied Microbiology and Biotechnology, 65: 2041-2048.

Baldi F., Pepi M., Capone A., Milanesi C., Fani R., Focarelli R. (2003). Envelope glycosylation determined by lectins in microscopy sections of Acinetobacter venetianus induced by diesel fuel. Research in Microbiology, 154: 417-424.

Banat I., Franzetti A., Gandolfi I., Bestetti G., Martinotti M., Fracchia L., Smyth T., Marchant R. (2010). Microbial biosurfactants production, applications and future potential. Applied Microbiology and Biotechnology, 87: 427-444. 
Barkay T., Navon-Venezia S., Ron E. Z., Rosenberg E. (1999). Enhancement of solubilization and biodegradation of Polyaromatic Hydrocarbons by the bioemulsifier alasan. Applied Microbiology and Biotechnology 65: 2697-2702.

Baumann P. (1968). Isolation of Acinetobacter from soiland water. Journal of Bacteriology, 96: $39-42$

Benavente R. G. (1999). Aceite Lubricante Usado. Bravo Energy Chile S.A. Boletín Nº 2.

Bihari Z., Pettko-Szandtner A., Csanadi G., Balazs M., Bartos P., Kesseru P., Kiss I., Mecs I. (2007). Isolation and characterization of a novel n-alkane-degrading strain, Acinetobacter haemolyticus AR-46. Journal of Biosciences, 62: 285-295.

Bouvet P. J. M., Bouvet O. M. M. (1989). Glucose dehydrogenase activity in Acinetobacter species. Research in Microbiology, 140: 531-540.

Brevedan M. I. V., Carelli A. A., Crapiste G. H. (2000). Changes in composition and quality of sunflower oils during extraction and degumming. Grasas y aceites, 51:417-423.

Cameotra S. S, y Makkar R. S. (1998). Synthesis of biosurfactants in extreme conditions. Applied Microbiology and Biotechnology, 50: 520-529.

Cameotra S.S. y Makkar R. S. (2010). Biosurfactant-enhanced bioremediation of hydrophobic pollutants. Pure and Applied Chemistry, 82: 97-116.

Cañipa-Morales N. K., Galán-Vidal C. A., Pérez Ortiz J. A., Guzmán Vega M. A. (2003) Clasificación de petróleos mexicanos mediante cromatografía de gases y análisis de componentes principales. Journal of the Mexican Chemical Society, 47: 275-282. 
Chamanrokh P., Mazaheri A. M., Noohi A., Yahyai S. (2008). Emulsan analysis produced by locally isolated bacteria and Acinetobacter calcoaceticus RAG-1. Iranian Journal of Environmental Health Science \& Engineering, 5: 101-108.

Chen J., Huang P. T., Zhang K. Y., Ding F. R. (2012). Isolation of biosurfactant producers, optimization and properties of biosurfactant produced by Acinetobacter sp. from petroleum-contaminated soil. Journal of Applied Microbiology, 112: 660-671.

Chisti Y. (1989). Airlift reactors: current technology de: Chisti Y. (Ed.), Airlift Bioreactors, Primera edición, Elsevier, Essex.: 33-86.

Desai J. D. y Banat I. M. (1997). Microbial production of surfactant and their commercial potential. Microbiology and Molecular Biology Reviews, 61: 47-64.

Díaz-Ramírez I. J., Ramirez-Saad H., Gutierrez-Rojas M., Favela-Torres E. (2003). Biodegradation of Maya crude oil fractions by bacterial strains and a defined mixed culture isolated from Cyperus laxus rhizosphere soil in a contaminated site. Canadian Journal of Microbiology, 49: 755-761.

Dominguez-Rosado E. y Pichtel J. (2003) Chemical characterization of fresh, used and weathered motor oil via GG/MS, NMR and FTIR techniques. Proceedings of the Indiana Academy of Science, 112: 109-116.

Doughari H. J., Ndakidemi P. A., Human I. S., Benade S. (2011). The ecology, biology and pathogenesis of Acinetobacter spp.: an overview. Microbes and Environments, 25: 101112. 
Dumont M. J., Narine S. S., (2007). Soapstock and deodorizer distillates from North American vegetable oils: Review on their characterization, extraction and utilization. Food Research International, 40: 957-974.

Franzetti A., Tamburini E., Banat I. (2010). Applications of biological surface active compounds in remediation technologies. Advances in Experimental Medicine and Biology. Biosurfactants. Editorial Ramkrishna Sen. Primera Edición. 672: 236-249.

Gompertz, B. (1825). On the nature of the function expressive of the law of human mortality, and on a new mode of determining the value of life contingencies. Philosophical Transactions of the Royal Society, 115: 513-585.

Hall C., Harakan P., Hallock J. (2003). Hydrocarbons and the evolution of human culture. Nature, 426: 318-322.

Hasan F., Shah A. A., Hameed A. (2006). Industrial applications of microbial lipases. Enzime and Microbial Technology, 39: 235-251.

Hori K., Matsuzaki Y., Tanji Y., Unno H. (2002). Effect of dispersing oil phase on the biodegradability of a solid alkane dissolved in non-biodegradable oil. Applied Microbiology and Biotechnology, 59:574-579.

Instituto Mexicano del Petróleo (IMP) (2011). Tipos de petróleo. Datos recuperados el 29 de marzo de 2012 de http://www.imp.mx/petroleo/?imp=tipos 
Ishige T., Tani A., Sakai Y., Kato N. (2000). Long-chain aldehyde dehydrogenase that participates in n-Alkane utilization and wax ester synthesis in Acinetobacter sp. Strain M-1. Applied and Environmental Microbiology, 66: 3481-3486.

Jaeger K. y Eggert T. (2002). Lipases for biotechnology. Current Opinion in Biotechnology, 13: 390-397.

Jagtap S., Yavankar S., Pardesi K., Chopade B. (2010). Production of bioemulsifier by Acinetobacter species isolated from healthy human skin. Indian Journal of Experimental Biology, 48: 70-76.

Juni E. (1978). Genetics and physiology of Acinetobacter. Annual Review of Microbiology, 32: 349-371.

Knothe G. y Steidley K. R. (2009). A comparison of used cooking oils: A very heterogeneous feedstock for biodiesel. Bioresource Technology, 100: 5797-5801.

Kosaric N. (1992). Biosurfactants in industry. Pure and Applied Chemistry, 64: 1731-1737.

Lizardi-Jiménez M. A., Gutiérrez-Rojas M. (2011). Evaluación de las zonas hidrodinámicas locales en un reactor airlift trifásico: buscando el Re de fase líquida más bajo. Revista Mexicana de Ingeniería Química, 10: 59-65.

Lizardi-Jiménez M. A., Saucedo-Castañeda G., Thalassob F., Gutiérrez-Rojasa M. (2012). Simultaneous hexadecane and oxygen transfer rate on the production of an oil-degrading consortium in a three-phase airlift bioreactor. Chemical Engineering Journal, 187: 160165. 
Makkar R. S., Cameotra S. S., Banat I. M. (2011). Advances in utilization of renewable substrates for biosurfactant production. AMB Express, 1: 1-19.

Martínez-Valencia B. B., Solis-Bonilla J. L., Zamarripa-Comenero A. (2011). Calidad agroindustrial de aceite de higerilla (Recinus comunis L.) para la producción de bioenergeticos. Recuperado el 1 de marzo del 2012 de http://www.bioenergeticos.gob.mx

Medina-Moreno S. A., Huerta-Ochoa S., Gutiérrez-Rojas M. (2005). Hydrocarbon biodegradation in oxygen-limited sequential batch reactors by consortium from weathered, oil-contaminated soil. Canadian Journal of Microbiology, 51: 231-239.

Medina-Moreno S. A., Jiménez-González A., Gutiérrez-Rojas M., Lizardi-Jiménez M. A. (2013). Hexadecane aqueous emulsion characterization and uptake by an oil-degrading microbial consortium. International Biodeterioration and Biodegradation, 84: 1-7.

Mohamed N. D. A., Nazrizawati A. T., Mohamed F. M. Y., Noraishah A., Salimon J. (2010). Fatty acid composition and physicochemical properties of Malaysian castor bean Ricinus communis L. Seed Oil. Sains Malaysiana, 39: 761-764.

Motulsky H. J. y Ransnas L. A. (1987). Fitting curves to data using nonlinear regression: a practical and nonmathematical review. The Journal of Federation of American Societies for Experimental Biology. 1: 365-374.

Mukherjee S., Das P., Sen R. (2006) Towards commercial production of microbial surfactants. Trends in Biotechnology, 24: 509-515. 
Navon-venezia S., Zosim Z., Gottlieb A., Legmann R., Carmell S., Ron E.Z., Rosenberg, E. (1995). Alasan, a new bioemulsifier from Acinetobacter radioresistens. Applied and Environmental Microbiology, 61: 3240-3244.

Noah, K. S., Fox S. L., Bruhn D. F., Thompson D. N., Bala G. A. (2002). Development of continuous surfactin production from potato process effluent by Bacillus subtilis in an airlift reactor. Applied Biochemistry and Biotechnology, 98: 803-813.

Patil J. y Chopade B. (2001). Studies on bioemulsifier production by Acinetobacter strains isolated from healthy human skin. Journal of Applied Microbiology, 91: 290-298.

Pacwa-Plociniczak M., Plaza G. A., Piotrowska-Seget Z., Cameotra S. S. (2011). Environmental Applications of Biosurfactants: Recent Advances. International Journal of Molecular Sciences, 12: 633-654.

Petróleos Mexicanos (PEMEX) (2012). Reservas de hidrocarburos en México. PEMEX Exploración y Producción, edición 2012.

Phetrong K., H-Kittikun A., Maneerat S. (2008). Production and characterization of bioemulsifier from a marine bacterium, Acinetobacter calcoaceticus subsp. anitratus SM7. Songklanakarin Journal Science Technology, 30: 297-305.

Pirog T., Sofilkanych A., Konon A., Shevchuk T., Ivanov S. (2013). Intensification of surfactants' synthesis by Rhodococcus erythropolis IMV Ac-5017, Acinetobacter calcoaceticus IMV B-7241 and Nocardia vaccinii K-8 on fried oil and glycerol containing medium. Food and Bioproducts processing, 91: 149-157. 
Ramezani K., Rowshanzamir S., Eikani M. H. (2010). Castor oil transesterification reaction: A kinetic study and optimizate parameters. Energy, 35: 4142-4148.

Rosenberg E., Perry A., Gibson D. T., Gutnick D. L. (1979). Emulsifier of Arthrobacter RAG1: specificity of hydrocarbon substrate. Applied and Environmental Microbiology, 37: 409-413.

Rosenberg E., Zuckerberg A., Rubinovitz C., Gutnick D. L. (1979b). Emulsifier of Arthrobacter RAG-1: isolation and emulsifying properties., 37(3):402. Applied and Environmental Microbiology, 37: 402-408.

Rosenberg E. y Ron E. Z. (1997) Bioemulsans: microbial polymeric emulsifiers. Current Opinion in Biotechnology, 8: 313-316.

Satpute S. K., Banpurkar A. G., Dhakephalkar P. K., Banat I. M., Chopade B. A. (2010). Methods for investigating biosurfactants and bioemulsifiers: a review. Critical Reviews in Biotechnology, 1-18.

Sar N. y Rosenberg E. (1983). Emulsifier production by Acinetobacter calcoaceticus strains. Current Microbiology, 9: 309-314.

SEMARNAT (2012). Generación estimada de residuos peligrosos según clasificación de residuos. Recuperado el 3 de febrero de 2011, de http://www.semarnat.gob.mx.

Shah V., Jurjevic M., Badia D. (2007). Utilization of restaurant waste oil as aprecursor for sophorolipid production. Biotechnolgy Progress, 23: 512-515. 
Snellman E. A., Sullivan E. R., Colwell R. R. (2002). Purification and properties of extracellular lipase, lipA, of Acinetobacter sp. RAG-1. European Journal of Biochemistry, 269: 57715779.

Su W., Chen W. Lin Y. (2009). Optimizing emulsan production of A. venetianus RAG-1 using response surface methodology. Applied Microbiology and Biotechnology, 84: 271-279.

Syldatk C., Hausmann R. (2010). Microbial biosurfactants. European Journal of Lipid Science and Technology, 112: 615-616.

Tanaka D., Takashima M., Mizuta A., Tanaka S., Sakatoku A., Nishikawa A., Osawa T. Noguchi M., Aizawa S., Nakamura S. (2010). Acinetobacter sp. Ud-4 Efficiently degrades both edible and mineral oils: Isolation and characterization. Current Microbiology, 60: 203-209.

Tzintzun-Camacho O., Loera O., Ramírez-Saad H. C., Gutiérrez-Rojas M. (2012). Comparison of mechanisma of hexandecane uptake amog pure and mixed cultures from a bacterial consortium. International Biodeterioration \& Biodegradation, 70: 1-7.

Van Bogaert I., Saerens K., De Muynck C., Develter D., Soetaert W., Vandamme E., (2007). Microbial production and application of sophorolipids. Applied Microbiology and Biotechnology, 76: 23-34.

Velasco-Alvarez N., González I., Damian-Matsumura P., Gutiérrez-Rojas M. (2011). Enhanced hexadecane degradation and low biomass production by Aspergillus niger exposed to an electric current in a model system. Bioresource Technology, 102: 1509-1515. 
Warskow A. L., Juni E. (1972). Nutritional requirements of strains isolated Acinetobacter from Soil, Water, and Sewage. Journal of Bacteriology, 112:1014-1016.

Whang L. M., Liu P. W. G., Ma C. C., Cheng S.S. (2008). Application of biosurfactant, rhamnolipid, and surfactin, for enhanced biodegradation of diesel-contaminated water and soil. Journal of Hazardous Materials, 151: 155-163.

Zwietering M. H., Jongenburger I., Rombouts F., Van’t Riet K. (1990). Modeling of the bacterial growth curve. Applied and Environmental Microbiology, 56:1875-1881. 